National Water-Quality Assessment Program

\title{
Nutrients in Streams and Rivers Across the Nation - 1992-2001
}

Scientific Investigations Report 2006-5107

U.S. Department of the Interior

U.S. Geological Survey 


\section{Nutrients in Streams and Rivers Across the Nation - 1992-2001}

By David K. Mueller and Norman E. Spahr

National Water-Quality Assessment Program

Scientific Investigations Report 2006-5107 


\section{U.S. Department of the Interior DIRK KEMPTHORNE, Secretary \\ U.S. Geological Survey P. PATRICK LEAHY, Acting Director}

U.S. Geological Survey, Reston, Virginia: 2006

For product and ordering information:

World Wide Web: http://www.usgs.gov/pubprod

Telephone: 1-888-ASK-USGS

For more information on the USGS--the Federal source for science about the Earth, its natural and living resources, natural hazards, and the environment:

World Wide Web: http://www.usgs.gov

Telephone: 1-888-ASK-USGS

Any use of trade, product, or firm names is for descriptive purposes only and does not imply endorsement by the U.S. Government.

Although this report is in the public domain, permission must be secured from the individual copyright owners to reproduce any copyrighted materials contained within this report.

Suggested citation:

Mueller, David K., and Spahr, Norman E., 2006, Nutrients in streams and rivers across the Nation-1992-2001: U.S. Geological Survey Scientific Investigations Report 2006-5107, 44 p. 


\section{Foreword}

The U.S. Geological Survey (USGS) is committed to providing the Nation with accurate and timely scientific information that helps enhance and protect the overall quality of life and that facilitates effective management of water, biological, energy, and mineral resources (http://www.usgs.gov/). Information on the quality of the Nation's water resources is critical to assuring the long-term availability of water that is safe for drinking and recreation and suitable for industry, irrigation, and habitat for fish and wildlife. Population growth and increasing demands for multiple water uses make water availability, now measured in terms of quantity and quality, even more essential to the longterm sustainability of our communities and ecosystems.

The USGS implemented the National Water-Quality Assessment (NAWQA) Program in 1991 to support national, regional, and local information needs and decisions related to water-quality management and policy (http://water. usgs.gov/nawqa). Shaped by and coordinated with ongoing efforts of other Federal, State, and local agencies, the NAWQA Program is designed to answer: What is the condition of our Nation's streams and ground water? How are the conditions changing over time? How do natural features and human activities affect the quality of streams and ground water, and where are those effects most pronounced? By combining information on water chemistry, physical characteristics, stream habitat, and aquatic life, the NAWQA Program aims to provide science-based insights for current and emerging water issues and priorities.

From 1991 to 2001, the NAWQA Program completed interdisciplinary assessments in 51 of the Nation's major river basins and aquifer systems, referred to as Study Units (http://water.usgs.gov/nawqa/studyu.html). Baseline condi-

tions were established for comparison to future assessments, and long-term monitoring was initiated in many of the basins. During the next decade, 42 of the 51 Study Units will be reassessed so that 10 years of comparable monitoring data will be available to determine trends at many of the Nation's streams and aquifers. The next 10 years of study also will fill in critical gaps in characterizing water-quality conditions, enhance understanding of factors that affect water quality, and establish links between sources of contaminants, the transport of those contaminants through the hydrologic system, and the potential effects of contaminants on humans and aquatic ecosystems.

The USGS aims to disseminate credible, timely, and relevant science information to inform practical and effective water-resource management and strategies that protect and restore water quality. We hope this NAWQA publication will provide you with insights and information to meet your needs and will foster increased citizen awareness and involvement in the protection and restoration of our Nation's waters.

The USGS recognizes that a national assessment by a single program cannot address all water-resource issues of interest. External coordination at all levels is critical for a fully integrated understanding of watersheds and for cost-effective management, regulation, and conservation of our Nation's water resources. The NAWQA Program, therefore, depends on advice and information from other agencies-Federal, State, interstate, Tribal, and local一as well as nongovernmental organizations, industry, academia, and other stakeholder groups. Your assistance and suggestions are greatly appreciated.

Robert M. Hirsch

Associate Director for Water 


\section{Contents}

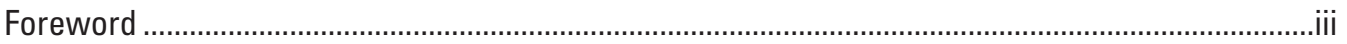

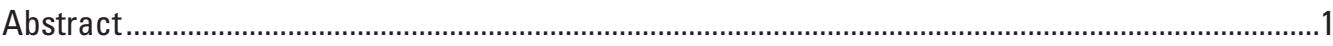

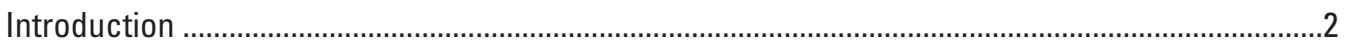

The National Water-Quality Assessment Program ………….....................................................

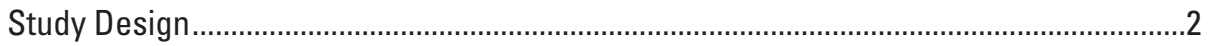

Sample Collection and Laboratory Analysis ................................................................

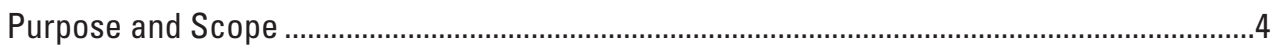

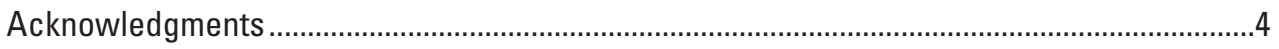

Methods Used to Characterize Nutrients in Streams and Rivers.................................................

Compilation of Environmental Sample Data ...........................................................................

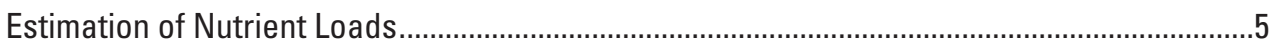

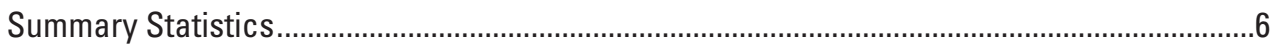

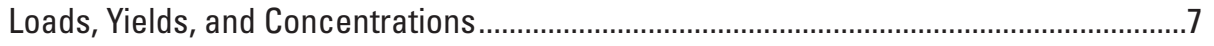

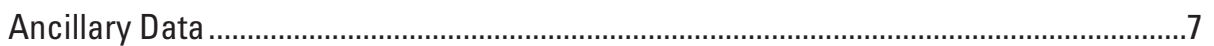

Comparison to Previous National Analyses ..........................................................................

Site Selection and the Problem of Representative Data........................................................

Nutrients in Streams and Rivers Across the Nation ...................................................................

Distribution of Nutrient Concentrations and Yields..........................................................10

Geographic Distribution of Nutrient Concentrations and Yields....................................10

Seasonal Distribution of Nutrient Concentrations and Streamflow.................................14

Relations between Nutrient Distributions and Land Use ...................................................27

Comparison of Nutrient Concentrations and Yields among Major Land Uses...............27

Comparison to Background Conditions ..........................................................................30

Relation of Nutrient Concentration, Yield, and Load to Sources in the Watershed .................34

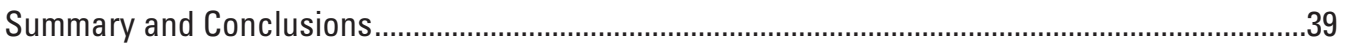

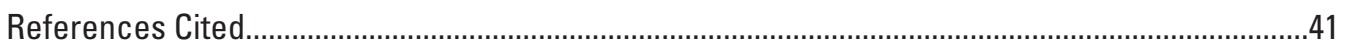

\section{Figures}

1-13. Maps showing:

1. Location of National Water-Quality Assessment study units investigated during 1992-200

2. Location of the 481 National Water-Quality Assessment sampling sites with adequate data for analysis of nutrient concentrations and loads

3. Areas of the continental United States, defined on the basis of water-source regions, as used in the report.

4. Flow-weighted concentrations of total nitrogen from agricultural, urban, undeveloped, and large watersheds

5. Flow-weighted concentrations of total phosphorus from agricultural, urban, undeveloped, and large watersheds.

6. Annual yield of total nitrogen from agricultural, urban, undeveloped, and large watersheds. 
7. Annual yield of total phosphorus from agricultural, urban, undeveloped, and large watersheds.

8. Distribution of high and low seasonal streamflow................................................22

9. Distribution of high and low seasonal concentrations of total nitrogen..................23

10. Distribution of high and low seasonal concentrations of total phosphorus............24

11. Distribution of high and low seasonal concentrations of ammonia. ........................25

12. Distribution of high and low seasonal concentrations of nitrate. ...........................26

13. Distribution of high and low seasonal concentrations of orthophosphate. ............28

14. Box plots showing the distribution of flow-weighted nutrient concentrations by land-use category

15. Box plots showing the distribution of nutrient yields by land-use category. ...................31

16. Box plots showing the distributions of flow-weighted mean nutrient concentrations in streams and rivers downstream from undeveloped watersheds and grouped by predominant type (forest or rangeland) of undeveloped land use.

17. Graph showing the relation of total phosphorus to suspended-sediment concentration at undeveloped sites.

18. Box plots showing the distributions of nutrient yields from undeveloped watersheds.

19. Map showing nutrient ecoregions of the continental United States, as defined by the U.S. Environmental Protection Agency (1998).

20. Box plots showing the distributions of total nitrogen and total phosphorus flow-weighted concentrations downstream from undeveloped watersheds by U.S. Environmental Protection Agency nutrient ecoregions.

21. Graphs showing the relation of nutrient inputs and outflow loads for selected National Water-Quality Assessment sites, with dashed lines showing apparent nutrient retention in the watershed.

22. Graphs showing LOWESS smooth curves of the general relation between nutrient inputs and outflow loads for watersheds in selected land-use categories.

\section{Tables}

1. Data sets that provide information supplemental to the analyses in this report...............5

2. General time periods used for model calibration and load estimation. ..............................7

3. Spearman correlation coefficients for modeled mean annual nutrient concentrations, yields, and loads with selected characteristics of the upstream watersheds. 


\section{Conversion Factors}

\begin{tabular}{lll}
\hline Multiply & By & To obtain \\
\hline kilometer $(\mathrm{km})$ & 0.6214 & mile $(\mathrm{mi})$ \\
centimeter $(\mathrm{cm})$ & 0.3937 & inch $(\mathrm{in})$ \\
square kilometer $\left(\mathrm{km}^{2}\right)$ & 247.1 & acre \\
square kilometer $\left(\mathrm{km}^{2}\right)$ & 0.3861 & square mile $\left(\mathrm{mi}^{2}\right)$ \\
cubic meter per second $\left(\mathrm{m}^{3} / \mathrm{s}\right)$ & 35.31 & cubic foot per second \\
& & $(\mathrm{ft} / \mathrm{s})$ \\
kilogram $(\mathrm{kg})$ & 2.205 & pound, avoirdupois $(\mathrm{lb})$ \\
kilogram per square kilometer $\left(\mathrm{kg} / \mathrm{km}^{2}\right)$ & 0.008921 & pound per acre $(\mathrm{lb} / \mathrm{acre})$ \\
\hline
\end{tabular}

Temperature in degrees Celsius $\left({ }^{\circ} \mathrm{C}\right)$ may be converted to degrees Fahrenheit $\left({ }^{\circ} \mathrm{F}\right)$ as follows:

$$
{ }^{\circ} \mathrm{F}=\left(1.8 \times{ }^{\circ} \mathrm{C}\right)+32
$$

Temperature in degrees Fahrenheit $\left({ }^{\circ} \mathrm{F}\right)$ may be converted to degrees Celsius $\left({ }^{\circ} \mathrm{C}\right)$ as follows: ${ }^{\circ} \mathrm{C}=\left({ }^{\circ} \mathrm{F}-32\right) / 1.8$

Latitude and longitude are referenced to the North American Datum of 1983 (NAD83).

Altitude, as used in this report, refers to distance above the North American Vertical Datum of 1988 (NAVD88).

Concentrations of chemical constituents in water are given in milligrams per liter $(\mathrm{mg} / \mathrm{L})$. 


\title{
Nutrients in Streams and Rivers Across the Nation - 1992-2001
}

\author{
By David K. Mueller and Norman E. Spahr
}

\section{Abstract}

Nutrient compounds of nitrogen and phosphorus were investigated in streams and rivers sampled as part of the U.S. Geological Survey National Water-Quality Assessment (NAWQA) Program. Nutrient data were collected in 20 NAWQA study units during 1992-95, 16 study units during 1996-98, and 15 study units during 1999-2001. To facilitate comparisons among sampling sites with variable sampling frequency, daily loads were determined by using regression models that relate constituent transport to streamflow and time. Model results were used to compute mean annual loads, yields, and concentrations of ammonia, nitrate, total nitrogen, orthophosphate, and total phosphorus, which were compared among stream and river sampling sites. Variations in the occurrence and distribution of nutrients in streams and rivers on a broad national scale reflect differences in the sources of nutrient inputs to the upstream watersheds and in watershed characteristics that affect movement of those nutrients.

Sites were classified by watershed size and by land use in the upstream watershed: agriculture, urban, and undeveloped (forest or rangeland). Selection of NAWQA urban sites was intended to avoid effects of major wastewater-treatment plants and other point sources, but in some locations this was not feasible. Nutrient concentrations and yields generally increased with anthropogenic development in the watershed. Median concentrations and yields for all constituents at sites downstream from undeveloped areas were less than at sites downstream from agricultural or urban areas. Concentrations of ammonia, orthophosphate, and total phosphorus at agricultural and urban sites were not significantly different; however, concentrations of nitrate and total nitrogen were higher at agricultural than at urban sites. Total nitrogen concentrations at agricultural sites were higher in areas of high nitrogen input or enhanced transport, such as irrigation or artificial drainage that can rapidly move water from cropland to streams (Midwest, Northern Plains, and western areas of the United States). Concentrations were lower in the Southeast, where more denitrification occurs during transport of nitrogen compounds in shallow ground water. At urban sites, high concentrations of ammonia and orthophosphate were more prevalent downstream from wastewater-treatment plants. At sites with large watersheds and high mean-annual streamflow ("large-watershed" sites), concentrations of most nutrients were significantly less than at sites downstream from agricultural or urban areas. Total nitrogen concentrations at large-watershed sites were higher in Midwest agricultural areas and lower in the Western United States, where agricultural and urban development is less extensive. Total phosphorus concentrations at large-watershed sites were higher in areas of greater potential erosion and low overall runoff such as the arid areas in the West.

Although not as distinct as seasonal patterns of streamflow, geographic patterns of seasonally high and low concentrations of total nitrogen and total phosphorus were identified in the data. Seasonal patterns in concentrations of total nitrogen generally mirror seasonal patterns in streamflow in the humid Eastern United States but are inverse to seasonal patterns in streamflow in the semiarid interior West. Total phosphorus concentrations typically have the opposite regional relation with streamflow; high concentrations coincide with high streamflows in the interior West.

In the NAWQA Program, sites downstream from relatively undeveloped areas were selected to provide a baseline for comparison to sites with potential effects of urban development and agriculture. Concentrations of nitrate, total nitrogen, and total phosphorus at NAWQA undeveloped sites were found to be greater than values reported by other studies for conditions of essentially no development (background conditions). Concentrations at NAWQA undeveloped sites represent conditions of relatively little development and provide insight in comparison to developed areas but should not, in general, be considered to represent background status.

The U.S. Environmental Protection Agency has developed nutrient criteria to assist States in setting regional waterquality standards. Regional criteria were exceeded by total nitrogen concentrations at 72 percent of NAWQA undeveloped sites and by total phosphorus concentrations at 89 percent of these sites. Exceedances were even more extensive at sites with greater anthropogenic development upstream. The nitrogen criteria were exceeded at 96 percent of NAWQA sites classified as agricultural, urban, or mixed land use, and the phosphorus criteria were exceeded at 97 percent of these sites.

Nationally, outflow loads of all nutrient constituents were strongly correlated to nonpoint-source inputs in the upstream 
watershed. The variation in input mass explained at least 69 percent of the variation in loads. Correlations between nonpoint-source input rates and outflow yields were not quite as good; variation in input rates explained only about 22-45 percent of the variations in nutrient yields. Estimation of nutrient outflow, on the basis of these correlations, likely could be improved if nationally consistent data were available for additional watershed characteristics.

\section{Introduction}

According to the most recent U.S. Environmental Protection Agency (USEPA) report on the state of the Nation's waters, nutrients were the fifth leading pollutant in rivers and streams, affecting 20 percent of impaired and 12 percent of assessed river miles (U.S. Environmental Protection Agency, 2002a). The USEPA report also lists nutrients as the leading pollutant in lakes and reservoirs and the third leading cause of degradation in wetlands and estuaries.

Nutrients are chemical compounds that contain nitrogen $(\mathrm{N})$ or phosphorus $(\mathrm{P})$. These compounds are essential to plant and animal nutrition, but in high concentrations they can be contaminants in water. Nutrient compounds are affected by chemical and biological processes that can change their form and can transfer them to or from water, soil, biological organisms, and the atmosphere.

Ammonia, a compound of nitrogen and hydrogen, is one of the forms of dissolved nitrogen in natural water. Depending on the number of hydrogen atoms in the compound, ammonia in water may be ionic (having an electrical charge) or unionized (having no charge). The un-ionized form is more toxic to fish. Ammonia is soluble in water but is not stable in most aquatic environments. It commonly is transformed to nitrate in water that contains oxygen and can be transformed to nitrogen gas in water that is low in oxygen.

Nitrate, a compound of nitrogen and oxygen, is another form of dissolved nitrogen in natural water. Nitrate is highly soluble in water and is stable over a wide range of environmental conditions, but can be reduced to nitrogen gas in the absence of oxygen. It is readily transported in ground water and streams.

Phosphates, including orthophosphate, are compounds of phosphorus, oxygen, and hydrogen and are the only significant form of dissolved phosphorus in natural water. Phosphates are only moderately soluble and tend to adhere to soil particles.

Relative to nitrate, phosphates are not very mobile in soil and ground water; however, erosion can transport considerable amounts of phosphate-laden particulates to streams and lakes.

An important negative effect of excessive nutrient concentrations is accelerated eutrophication of streams and receiving waters. Although the growth rate in many freshwater ecosystems is limited by phosphorus, nitrogen usually is more important in saltwater. In recent years, the Mississippi River has discharged as much as one million megagrams of dissolved nitrate-nitrogen annually into the Gulf of Mexico (Goolsby and Battaglin, 1995). Nitrate and other nutrients are suspected of causing a large zone of hypoxia (seasonally low dissolved-oxygen concentrations) along the Louisiana-Texas coast (Justic and others, 1993). Agriculture, specifically the use of nitrogen and phosphorus fertilizer, is a suspected cause of the Gulf of Mexico zone of hypoxia (Rabalais and others, 1996).

\section{The National Water-Quality Assessment Program}

Knowledge of the quality of the Nation's streams and aquifers is important because of the implications to human and aquatic health and because of the substantial costs associated with decisions involving land and water management, conservation, and regulation. Understanding regional patterns and environmental factors affecting nutrient concentrations in streams and shallow ground water is essential for effectively developing programs to manage and protect these water resources.

In 1991, the U.S. Congress appropriated funds for the U.S. Geological Survey (USGS) to begin the National WaterQuality Assessment (NAWQA) Program to help meet the continuing need for sound scientific information to address water-quality issues. Objectives of the NAWQA Program include understanding how water quality is changing with time and what effect human actions and natural factors have on water-quality conditions (Gilliom and others, 1995). These objectives are being achieved through investigations in 51 large river basins and aquifer systems, which are referred to as "study units." Implementation of study-unit investigations is phased so that high-intensity sampling occurs in about one-third of the study units concurrently. Investigations in the first 20 study units began in 1991, and stream sampling began in 1992; however, most samples were collected during water years 1993-95. (Water year is the period from October through September, and is identified by the year in which it ends.) A second group of 16 study units began in 1994, with most of the sampling completed during water years 1996-98. A third group consisting of 15 study units began in 1997 with most of the data collected during water years 1999-2001. The location of these 51 study units is shown in figure 1.

\section{Study Design}

Each NAWQA study-unit investigation team screened and reviewed available data on nutrients, pesticides, and associated environmental data for streams and ground water. These analyses were used to develop an environmental framework for selecting sampling locations to answer questions about agricultural and urban land-use effects on water quality. A study-unit stream-monitoring network typically included 10 to 12 locations, referred to as "fixed sites," which were routinely 


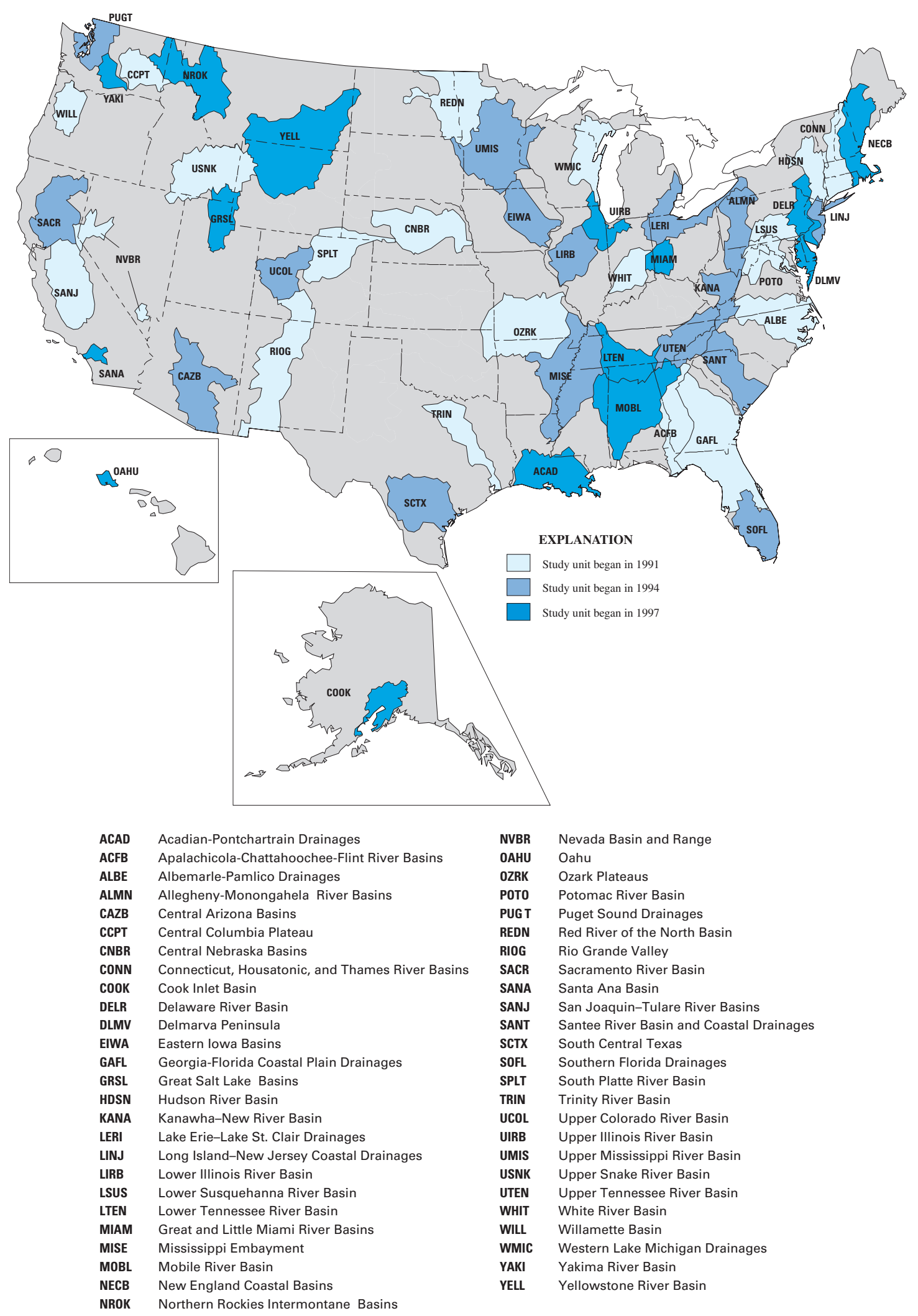

Figure 1. Location of National Water-Quality Assessment study units investigated during 1992-2001. 
sampled during the high-intensity phase. The upstream watersheds at about one-half of these sites were small, typically $50-1,000 \mathrm{~km}^{2}$, and had relatively homogeneous land use. The remaining sites were located at the outlets of larger watersheds that commonly contained multiple land uses and included a substantial percentage of the study-unit area. Gilliom and others (1995) provide additional information about study-unit sampling design.

\section{Sample Collection and Laboratory Analysis}

The basic sampling frequency at stream and river sites was monthly. In high-intensity sampling years, several additional high-flow samples were collected to characterize that part of the hydrograph where concentrations might be more variable. At subsets of sites, samples were collected more frequently during time periods when concentrations of certain constituents, primarily pesticides, were expected to be high. These sampling frequencies varied from biweekly to as often as every other day. Routine sampling included field blanks and replicates to assess measurement bias and variability (Mueller and others, 1997).

Typically, samples were collected using a depth-integrating sampler at multiple vertical locations in the stream cross section (Shelton, 1994; U.S. Geological Survey, variously dated). Samples for analysis of dissolved constituents were filtered in the field, within 2 hours of collection, through either a nitrocellulose filter or a polyether-sulfone medium with a pore size of 0.45 micrometer. Nutrient samples were chilled and maintained at 4 degrees Celsius until analyzed at the laboratory.

All samples were analyzed at the USGS National WaterQuality Laboratory (NWQL) in Colorado. Analyses were made for a suite of nitrogen $(\mathrm{N})$ and phosphorus $(\mathrm{P})$ constituents:

- Dissolved ammonium plus un-ionized ammonia, hereinafter referred to as "ammonia"

- Dissolved nitrite

- Dissolved nitrite plus nitrate as nitrogen, hereinafter referred to as "nitrate"

- Dissolved Kjeldahl nitrogen, consisting of ammonia plus organic $\mathrm{N}$

- Total Kjeldahl nitrogen

- Dissolved orthophosphate

- Dissolved phosphorus

- Total phosphorus

Ammonia, nitrite, nitrate, and orthophosphate were analyzed according to methods described by Fishman (1993). Kjeldahl nitrogen was analyzed as described by Patton and Truitt (1992). During 1992-98, total and dissolved phosphorus were analyzed using a modified Kjeldahl procedure (Patton and Truitt, 2000). In 1999 these analyses were changed to U.S. Environmental Protection Agency method 365.1, low-level persulfate digestion (U.S. Environmental Protection Agency, 1993).

\section{Purpose and Scope}

This paper describes methods used to characterize nutrients in terms of concentration, yield, and load at stream and river sites sampled for the NAWQA Program. The distribution of nutrients at these sites is compared to nonpoint sources and watershed characteristics. This analysis uses data collected by consistent methods during water years 1993-2001 within the 51 NAWQA study units shown in figure 1.

\section{Acknowledgments}

This report relies on water samples that were collected over a 10 -year period by hydrologists and hydrologic technicians in 51 NAWQA study units and analyzed by technicians at the USGS National Water Quality Laboratory in Denver, Colorado. Without all their diligent efforts, the data interpretation in this report would not have been possible. Joe Joy, of the Washington Department of Ecology, and Dale Robertson, of the USGS Wisconsin Water Science Center, provided valuable comments on the report. The authors also thank Mary Kidd for editorial review and Sharon Powers for manuscript preparation, layout, and illustration assistance.

\section{Methods Used to Characterize Nutrients in Streams and Rivers}

Two difficulties arise from the variability of sampling frequency at NAWQA stream and river sampling sites:

- Summary statistics, such as mean concentration, used to characterize a site might be biased because of variations in sampling frequency during the period of record, and

- Comparisons among sites might be biased because of different sampling frequencies and numbers of samples at different sites.

These difficulties can be avoided by using flow-weighted mean concentrations, but only if sampling was distributed over the hydrograph. Intensive sampling during high flow or low flow, such as was common at some NAWQA sites, might overemphasize one part of the hydrograph and yield a biased result.

Another method for decreasing bias in site characterization and comparison is to estimate a concentration value for each day of a common period of record, such as a particular 
water year, and compute a mean of these estimates. There is a long history of statistical models that have been proposed to make such estimates. The model selected for the present analysis is based on the rating-curve method (Cohn and others, 1989; Cohn, Caulder, and others, 1992; Cohn, Gilroy, and Baier, 1992; Crawford, 1991). This method uses multiple regression to relate constituent transport (load or mass discharge) to streamflow and time, measured in decimal years. Estimated daily loads can be summed for selected periods, generally months or years, and converted to flow-weighted concentrations using streamflow volumes for the same periods.

\section{Compilation of Environmental Sample Data}

More than 28,000 nutrient samples were collected during the NAWQA Cycle I time period (water years 1992-2001) at 500 NAWQA stream and river sites. Analytic results from these samples were compiled into a data set that is included in a digital report by Mueller and Spahr (2005). The data sets available in this report are listed in table 1.

Analytic results in the environmental data set were retrieved from the USGS National Water Information System (NWIS) database (http://waterdata.usgs.gov/nwis) during March-July 2002. Data for NAWQA sites were included even if they were collected separately from the NAWQA Program. In addition to nutrients, data are provided for streamflow (instantaneous at the time of sampling and mean daily for the sampling date), physical measurements (in-situ temperature and dissolved oxygen plus specific conductance and $\mathrm{pH}$ of the sample), and concentrations of suspended sediment and organic carbon (dissolved and particulate). Mean daily streamflow data were retrieved along with water-quality data or added to the data set by selecting values for sampling dates from the NWIS daily values database. For sites that were not located at USGS streamflow-gaging stations, NAWQA study- unit staff provided daily streamflow values from a non-USGS gage or by computation using more than one USGS gage.

\section{Estimation of Nutrient Loads}

The loads of selected nutrients at NAWQA sites were estimated using multiple-regression analysis. The specific method used for model calibration and load estimation is described by Runkel and others (2004). Separate regression models were calibrated for each constituent at each site. The dependent variable in each case was the natural logarithm of the constituent load, computed as the product of a measured concentration and the mean daily streamflow for the date of sample collection. The explanatory (independent) variables for each model were selected from a set of potential predictor variables:

- natural logarithm of streamflow, log (flow)

- $\log$ (flow) squared

- time, in decimal years

- sine of time

- cosine of time

- time squared

The variables log (flow) and time were centered by subtracting the mean from each value. Thus, the squared values of these variables are fit to a parabolic curve with an inflection point near the mean.

For each constituent at each site, models were fit using all possible combinations of these variables, and the best model was selected on the basis of the Akaike Information Criteria

Table 1. Data sets that provide information supplemental to the analyses in this report.

[Data available in digital format from Mueller and Spahr (2005); NAWQA, National Water-Quality Assessment Program]

\begin{tabular}{lc}
\hline \multicolumn{1}{c}{ Data set } & \multicolumn{1}{c}{ Brief description } \\
\hline Environmental samples & $\begin{array}{c}\text { Nutrient samples, including selected other data, collected } \\
\text { during water years 1992-2001 at NAWQA stream and } \\
\text { river sampling sites. } \\
\text { Load-model coefficients } \\
\text { Regression coefficients and selected diagnostics for models } \\
\text { of nutrient loads at NAWQA sampling sites. }\end{array}$ \\
Daily streamflow & $\begin{array}{c}\text { Daily values of streamflow used to estimate nutrient loads } \\
\text { for selected water years at NAWQA sampling sites. } \\
\text { Mean annual loads, yields, and concentrations of five nutri- } \\
\text { ent constituents, plus selected ancillary data, at NAWQA } \\
\text { sampling sites. }\end{array}$ \\
\hline
\end{tabular}


(Akaike, 1981). The sine and cosine terms, which account for seasonality, were always included together if either was selected.

Because nutrient concentrations included censored values, regression coefficients were determined by an adjusted maximum-likelihood estimation (AMLE) method (Cohn, Gilroy, and Baier, 1992). The AMLE method corrects for bias in the standard maximum-likelihood (MLE) regression coefficients and also incorporates a factor that minimizes the bias that can occur when estimated logarithms of constituent load are retransformed to original units. For some constituents at some sites, a model could not be fit using the AMLE method; however, an MLE model was successful. In these cases, retransformation bias was corrected using the method of Bradu and Mundlak (1970).

Load models were developed for five nutrient constituents: ammonia, nitrate, total nitrogen, orthophosphate, and total phosphorus. Concentrations of total nitrogen (TN) were computed using the analytic results for dissolved nitrite plus nitrate $\left(\mathrm{NO}_{2}+\mathrm{NO}_{3}\right)$ and for total Kjeldahl nitrogen (TKN), which includes organic nitrogen and ammonia. If neither $\mathrm{NO}_{2}+\mathrm{NO}_{3}$ nor TKN was censored, $\mathrm{TN}$ was simply their sum. If one or the other was less than a method detection limit (MDL), the following rules were applied:

- If TKN is not censored and $\mathrm{NO}_{2}+\mathrm{NO}_{3}$ is censored, then $\mathrm{TN}=\mathrm{TKN}+0.5 \mathrm{X}\left(\mathrm{MDL}\right.$ for $\left.\mathrm{NO}_{2}+\mathrm{NO}_{3}\right)$.

- If TKN is censored and $\mathrm{NO}_{2}+\mathrm{NO}_{3}$ is greater than 0.20 , then $\mathrm{TN}=\left(\mathrm{NO}_{2}+\mathrm{NO}_{3}\right)+0.5 \mathrm{X}(\mathrm{MDL}$ for $\mathrm{TKN})$.

- If TKN is censored and $\mathrm{NO}_{2}+\mathrm{NO}_{3}$ is less than 0.20 , then $\mathrm{TN}=<0.20$.

The most common detection limits during water years 19922001 were $0.2 \mathrm{mg} / \mathrm{L}$ for $\mathrm{TKN}$ and $0.05 \mathrm{mg} / \mathrm{L}$ for $\mathrm{NO}_{2}+\mathrm{NO}_{3}$.

Regression models were calibrated using nutrient concentrations from samples collected at NAWQA sites during high-intensity sampling and mean-daily streamflow for the date of sampling. Standard errors of the mean seasonal and annual loads were calculated using a jackknife method (Efron, 1982) for AMLE models or the method described by Likes (1980) for MLE models. For each load model, residual distribution was evaluated using a goodness-of-fit test described by Turnbull and Weiss (1978). Maximum-likelihood estimates can be biased if residual distribution is not normal. The null hypothesis of the Turnbull-Weiss test is normality; therefore a low probability level ( $p$-value) for the test is evidence of a non-normal distribution.

The best model for each nutrient constituent at each site was selected based on the following priority:

1. The AMLE model was selected if the standard error for annual load was less than 75 percent of the mean and the p-value for the Turnbull-Weiss test was greater than 0.01 .
2. If the AMLE model was not selected, the MLE model was selected if the standard error for annual load was less than 75 percent of the mean and the $\mathrm{p}$-value for the Turnbull-Weiss test was greater than 0.01 .

3. If neither model was selected in steps 1 or 2 , the AMLE model was selected if the standard error was less than 75 percent of the mean, regardless of the Turnbull-Weiss test.

4. If no model was previously selected, the MLE model was selected if the standard error was less than 75 percent of the mean, regardless of the TurnbullWeiss test.

5. If no model was selected in steps 1-4 the model was considered a poor fit.

6. For nutrient constituents with fewer than six uncensored concentrations, model calibration was not attempted.

For some constituents, the model chosen by the Akaike Information Criteria had an unacceptably high standard error, but an alternative model was found to be acceptable. Regression coefficients and several diagnostics for the selected AMLE and MLE models are available in digital format in the "Loadmodel coefficients" data set described in table 1 .

If an AMLE or MLE model was selected, daily streamflows at the site were used to estimate daily nutrient loads for specified water years. Daily streamflow values used in these calculations are available in the "Daily streamflow" data set described in table 1. Using these load estimates, nutrient concentrations were calculated for each date as a ratio of the daily load and streamflow. The daily estimates can have large errors, but positive and negative errors tend to cancel out over a longer time period. Thus sums or averages of the daily values tend to have a greater accuracy. The time periods used for calibration of the models and for estimation of daily loads and concentrations are listed in table 2.

\section{Summary Statistics}

Nutrient-load model results were used to compute a number of summary statistics, which were then used to make comparisons among sites. These statistics include mean annual loads, yields, and concentrations for each nutrient constituent at each site, with the following exceptions. Two sites in the San Joaquin Valley of California were on sloughs draining the same area and were considered a single site. Eighteen other sites had insufficient data for model calibration; 12 of these had fewer than 18 samples during the high-intensity period, and another 6 had no complete water year of daily streamflow 
Table 2. General time periods used for model calibration and load estimation.

\begin{tabular}{cccccc}
\hline & $\begin{array}{c}\text { Nutrient load modeling period } \\
\text { (water years) }\end{array}$ & & \multicolumn{2}{c}{$\begin{array}{c}\text { Ancillary-data period } \\
\text { (calendar years) }\end{array}$} \\
\cline { 1 - 1 } \cline { 5 - 6 } $\begin{array}{c}\text { Study-unit } \\
\text { group } \\
\text { (start year }\end{array}$ & $\begin{array}{c}\text { Model } \\
\text { calibration }\end{array}$ & $\begin{array}{c}\text { Load } \\
\text { estimation }\end{array}$ & & $\begin{array}{c}\text { Fertilizer application } \\
\text { and atmospheric } \\
\text { deposition }\end{array}$ & $\begin{array}{c}\text { Manure } \\
\text { accumulation }\end{array}$ \\
\hline 1991 & $1993-1996$ & $1994-1995$ & & $1993-1995$ & 1992 \\
1994 & $1996-1999$ & $1997-1998$ & & $1996-1998$ & 1997 \\
1997 & $1999-2001$ & $2000-2001$ & & $1999-2001$ & 2002 \\
\hline
\end{tabular}

values. The resultant summary data set includes statistics for five nutrient constituents at 481 sites. These data are available in the "Summary" data set described in table 1. Locations of the 481 sampling sites are shown in figure 2 .

\section{Loads, Yields, and Concentrations}

For nutrients that could be fit to a regression model, mean annual load in kilograms $(\mathrm{kg})$ was estimated as the sum of the daily load values for the estimation period divided by the number of years. Mean annual yield in kilograms per square kilometer $\left(\mathrm{kg} / \mathrm{km}^{2}\right)$ was estimated by dividing the mean annual load by the upstream watershed area. The flow-weighted mean concentration in milligrams per liter $(\mathrm{mg} / \mathrm{L})$ was calculated by dividing the total load over the estimation time period by the total streamflow. The time-weighted mean concentration was calculated as the average of the daily concentrations for the same time period. Time-weighted concentration is similar to flow-weighted concentration at many sites. However, at some sites where streamflow and load are affected by large storm events, the time-weighted concentration can differ from the flow-weighted concentration and represents the more common condition.

For some nutrients, the calculated mean concentrations were less than the most common detection limit. In these cases, the yield and load estimates were retained, but the mean concentration was revised to less than detection.

In cases where a regression model could not be calibrated, the nutrient concentrations were plotted relative to streamflow and time. If there were no obvious curves or slopes in these relations, a mean concentration was computed. For nutrients with fewer than six uncensored concentrations, the flow-weighted and time-weighted mean concentrations were set to less than the most common detection limit. In these cases, load and yield were not calculated. For nutrients with more than six uncensored concentrations, a mean and standard error were computed using censored data techniques described by Helsel and Cohn (1988). If the standard error was less than 40 percent of the mean, the flow-weighted and time-weighted mean concentrations were set equal to the computed mean. Mean annual load was then calculated as the product of the flow-weighted mean, the total streamflow for the estimation period, and an appropriate units-conversion factor.
Mean annual yield was estimated by dividing the load by the upstream watershed area, in square kilometers.

\section{Ancillary Data}

The summary data set also contains selected ancillary data for the watershed upstream from each site. Land-use data include a classification into one of six categories as well as the percentages of major land-cover classes. These percentages were determined from National Land Cover Data (NLCD) digital maps, as revised by Nakagaki and Wolock (2005). Land-use categories are based primarily on land cover but are modified in some cases on the basis of local conditions, such as the presence of major point sources. In general, the land cover upstream from sites in the "Ag" category is more than 50 percent agricultural (cropland plus pasture) and less than 5 percent urban. Land cover upstream from sites in the "Urban" category usually is more than 25 percent urban and less than 25 percent agricultural. "Undeveloped" sites are downstream from land cover less than 25 percent agricultural and less than 5 percent urban. For sites in the "Mixed" category, there are substantial percentages of both agricultural (greater than 25 percent) and urban (greater than 5 percent) land cover upstream. Sites with moderate percentages of either agricultural ( 25 to 50 percent) or urban (5 to 25 percent) land cover are classified as partially developed ("Partial").

In large watersheds, the effects of specific land uses can be moderated by a complex mixture of land cover, multiple point sources, and temporally variable sources of streamflow. Thus, 105 sites were classified as "Large" on the basis of a combination of upstream watershed area and long-term mean annual streamflow. The criteria for this classification were:

- Mean annual streamflow greater than about $85 \mathrm{~m}^{3} / \mathrm{s}$ $\left(3,000 \mathrm{ft}^{3} / \mathrm{s}\right)-81$ sites with a minimum watershed area of about $1,500 \mathrm{~km}^{2}$, or

- Watershed area greater than $5,000 \mathrm{~km}^{2}$ and mean annual streamflow greater than about $57 \mathrm{~m}^{3} / \mathrm{s}$ $\left(2,000 \mathrm{ft}^{3} / \mathrm{s}\right)-17$ additional sites, or 


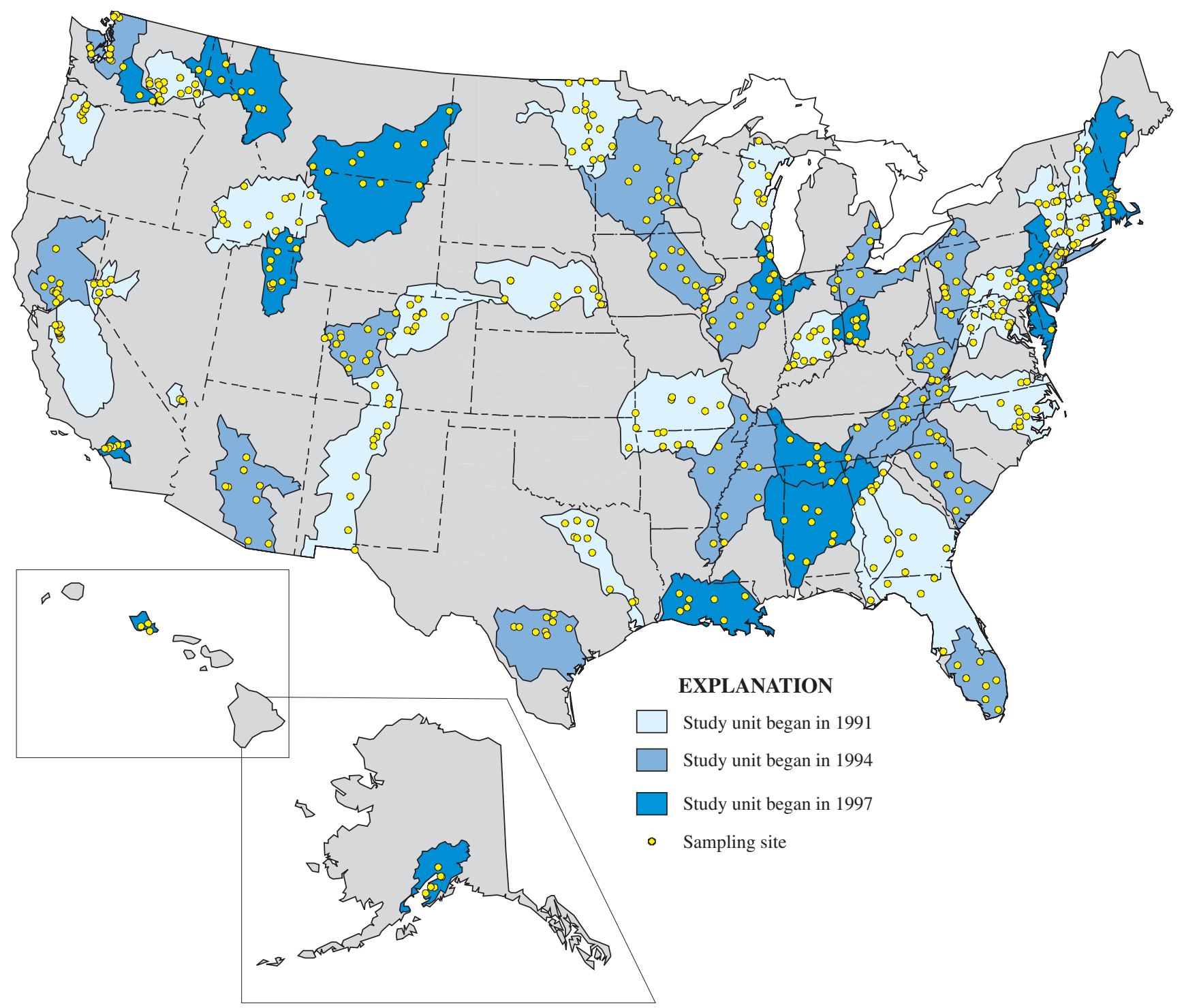

Figure 2. Location of the 481 National Water-Quality Assessment sampling sites with adequate data for analysis of nutrient concentrations and loads.

- Watershed area greater than $25,000 \mathrm{~km}^{2}$ and mean annual streamflow greater than about $14 \mathrm{~m}^{3} / \mathrm{s}$ $\left(500 \mathrm{ft}^{3} / \mathrm{s}\right)-7$ additional sites.

The selected sites represent watersheds that are large, in terms of area and streamflow, relative to other watersheds in the NAWQA Program. However, even the largest of these NAWQA sites have a much smaller area and streamflow than many sites that are sampled for other programs on major rivers of the Nation.

Land-cover data were incomplete or unavailable for a few sites. At six sites, more than 10 percent of the upstream area is in Canada or Mexico, which are not included in the
NLCD coverage. Also, nine sites in Alaska and Hawaii have no NLCD coverage. Land-use categories for these sites were determined on the basis of local information provided by the study unit teams. In addition, the classifications for 45 other sites were modified on the basis of local information, such as the presence of point sources in the watershed.

Nonpoint-source nutrient inputs are based on county-level estimates from Ruddy and others (2006). Inputs include nitrogen and phosphorus in commercial fertilizers used on farms and in urban settings, nitrogen and phosphorus in livestock manure, and nitrogen in atmospheric deposition. Estimates of fertilizer and manure inputs were assigned to specified NLCD land uses within each county and then summed for the area 
within each watershed boundary using methods similar to those described by Nakagaki and Wolock (2005). Estimates of atmospheric input were assumed to be uniform over the county, and an area-weighted sum was computed for each watershed.

\section{Comparison to Previous National Analyses}

The NAWQA Program previously has produced four national reports that include analyses of nutrients in streams. Mueller and others (1995) and Mueller and Helsel (1996) analyzed historical data collected in the first 20 NAWQA study units during 1980-90, the decade prior to NAWQA sampling. This data set included more than 22,000 samples from more than 300 sites. These sites were selected for a variety of purposes, and any consistency in the sampling design was merely coincidental. Temporal distribution of samples from individual sites varied widely, both annually and over the period of record. Spatial distribution of sites was limited to the area encompassed by study units that began their highintensity effort in 1991 (see map in fig. 1), and sites were not uniformly distributed. Nationally consistent ancillary data were not available for these sites; therefore, land-use classification was based on the best professional judgment of the local study-unit staff. Other ancillary data, such as population density and soil characteristics, were provided for some, but not all, watersheds. Overall, these inconsistencies limited the effectiveness of statistical analysis of the data. Site selection and sample collection in the NAWQA Program were designed to overcome these limitations.

The first national summary of NAWQA data included analyses of nutrient data from the first 20 study units (U.S. Geological Survey, 1999). These analyses were based on samples collected during water years 1993-95 from 212 sites in various land-use settings within each study unit. These sites were selected to represent streams where nutrient input was predominantly from nonpoint sources. Sample collection and sampling frequency were designed to be consistent among all sites (Shelton, 1994; Gilliom and others, 1995). Ancillary data, including land use, nutrient inputs, and soil characteristics, were derived from national Geographic Information System (GIS) maps. Thus, many of the inconsistencies that plagued the earlier national studies were eliminated. However, the spatial distribution of sites was still limited to areas of the study units that started work in 1991.

Separate reports were produced during 1998-2004 summarizing findings in each of the 51 NAWQA study units. These reports are available online at: http://water.usgs. gov/nawqa/nawqasum/. Hamilton and others (2004) provided an overview of selected findings from these reports. They presented results for a series of examples from individual study units, although these included only one example of nutrients in streams.

The current report is based on nationally consistent analyses of nutrient data collected at 481 NAWQA sampling sites in 51 study units during water years 1993-2001. The NAWQA design provided for consistent site-selection criteria and sample collection. Ancillary data were determined from national GIS maps. The data analyses used in this report avoid the inconsistencies of the previous national studies and have a broader spatial distribution than the individual NAWQA studyunit summary reports.

\section{Site Selection and the Problem of Representative Data}

Sampling sites within each NAWQA study unit were selected on the basis of a stratified design. The first level of stratification within a study unit generally was either physiographic region or ecoregion. A second level of stratification was land use, primarily agricultural, urban, or undeveloped (forest and rangeland). In some study units, land uses were subdivided into multiple categories, such as various types of agricultural or urban settings. Individual strata were determined by relatively homogeneous combinations of land use and physical characteristics, such as soil type and bedrock. Candidate sampling sites were then identified within each stratum. In theory, sampling one site within each stratum would provide data representative of the range of conditions within each study unit and, by extension, throughout the Nation. In practice, a number of factors prevented implementation of a nationally representative design.

Cost was the primary factor that limited implementation of a representative design. Sampling a site in every stratum in every study unit would be prohibitively expensive, so the original NAWQA objectives focused on areas where waterquality issues had regional or national significance (Gilliom and others, 1995). For example, 28 relatively homogeneous areas were identified in the Western Lake Michigan Drainages study unit, but on the basis of major water-quality issues, sampling sites were selected in only 8 of these areas (Sullivan and others, 1995). NAWQA staff worked with local, State, and Federal agencies, as well as the National Academy of Sciences, to identify important issues. The national issue most influential in site selection was nonpoint sources of nutrients and pesticides, so many sampling sites were selected downstream from agricultural or urban areas, where nutrient fertilizers and pesticides commonly are used. In urban areas, site selection was focused on residential areas, and attempts were made to avoid watersheds with point sources. Sites in undeveloped areas were selected for comparison to the agricultural and urban sites, and were intended to be similar in all aspects except land use. Thus, the NAWQA sampling network was designed to represent certain types of settings that occur throughout the Nation, but not necessarily to represent the entire Nation.

Many local considerations caused variable implementation of the NAWQA design among study units. Selection of some sites was driven by local concerns, for example, to address a specific water-quality issue or maintain sampling at 
a specific location. Another common consideration was the availability of good sampling locations. In arid and semiarid areas it was not always possible to find a site on a perennial stream in a homogeneous agricultural or urban setting. In the most intensive agricultural areas, it was difficult to find undeveloped reference sites. In many study units, it was difficult to avoid sites downstream from anthropogenic features, such as reservoirs and canals, which add complexity to delineation of nutrient sources in the watershed. This was a particular problem in the Western United States, where irrigation is common, and in southern Florida and Louisiana, where drainage and navigation canals cross relatively flat watersheds. Point sources could not always be avoided. Even some sites in agricultural areas with little population in the upstream watershed turned out to have significant amounts of wastewater effluent piped in from adjacent watersheds. Climate was another influential factor. At most sites, data were adequate to model nutrient loads over at least a 2-year period, so the effects of climate variation could be diminished. However, some sites had only 1 year of adequate streamflow data, and if that year happened to be particularly wet or dry, the load-model results might not represent average conditions at the site. All these factors tend to increase the variability of nutrient data in the NAWQA stream-sampling network. Thus, in some of the following analyses it was necessary to subdivide the network of sites in an attempt to limit the variability of data subsets and thus better represent certain conditions and settings.

\section{Nutrients in Streams and Rivers Across the Nation}

\section{Distribution of Nutrient Concentrations and Yields}

The distribution of nutrients in streams and rivers across the Nation can be described spatially and temporally. Geographic patterns in nutrient concentrations and yields and the relation of land use to concentrations and yields provide the framework to assess areas of potential concern. Seasonal variation in nitrogen and phosphorus concentrations can be used to describe national and regional patterns.

\section{Geographic Distribution of Nutrient Concentrations and Yields}

Discussion of geographic distribution requires a spatial framework with a defined terminology to delineate different areas. For the purposes of this report, the continental United States was divided into eight contiguous areas based on waterresource regions (fig. 3). Seaber and others (1987) used the boundaries of major river basins to define 21 water-resources regions. The areas designated in figure 3 are either single water-resources regions or combinations of regions. These area designations are used in the following discussion of geographic distribution. Alaska and Hawaii, not shown in figure 3, are individual regions and will be discussed as separate areas.

The spatial distributions of flow-weighted mean annual concentrations and mean annual yields for total nitrogen and total phosphorus are shown on a series of national maps. Individual maps show the relative range (high, medium, or low) of concentrations or yields for sites downstream from specified land uses. Breakpoints for the ranges shown on these maps were determined by percentages of concentration and yield for the 481 sites in the "Summary" data set described in table 1. Sites where concentration or yield was within the lower onethird of the data distribution are shown in the "Low" range, sites where concentration or yield within the upper one-third are shown in the "High" range, all other sites are shown in the "Medium" range. Sites plotted on these maps are classified by major land use--agricultural, urban, and undeveloped (forest and rangeland). Sites classified as "Large," in terms of watershed area and mean streamflow (see "Ancillary Data" section of this report), also are shown. Sites with land uses classified as "Mixed" or "Partial" were included in determining percentages but are not shown on the maps. The background shading on the maps identifies nonpoint-source input rates of nitrogen and phosphorus, based on county-level data from Ruddy and others (2006). Input rates were divided into "high," "medium," and "low" categories determined by percentages of the data distributions, as was done for concentrations and yields.

Concentrations of total nitrogen generally are high to medium downstream from agricultural and urban areas and medium to low downstream from undeveloped areas (fig. 4). Within agricultural areas, concentrations were high at most sites in the Northeast, Midwest, and Northwest (fig. 4A). These sites are in areas that receive large annual inputs of nitrogen in the form of fertilizer, manure, and (in some cases) atmospheric deposition. In addition, high concentrations in the Midwest might be influenced by the prevalence of subsurface (tile) drains, which can provide a short flow path for applied nitrogen to move from fields to streams (Fenelon, 1998; Groschen and others, 2004). High concentrations at many sites in the Northwest might be influenced by large applications of irrigation water, which can accelerate movement of nitrogen to streams. Irrigation also could be a factor in high concentrations at sites in the Northern Plains, Southwest, and California. Most of the medium and low concentrations of total nitrogen in agricultural areas were at sites in the Southeast and Southern Plains. Inputs are more variable in these regions. Also, in many areas of the Southeast, water and nitrogen move from fields to streams through shallow ground-water systems that can contain substantial amounts of organic matter. In these settings, denitrification can cause a loss of nitrogen from water before it reaches a stream; therefore, concentrations can be relatively low in comparison to input.

Total nitrogen concentrations downstream from urban areas generally were in the medium range, but sites with high 


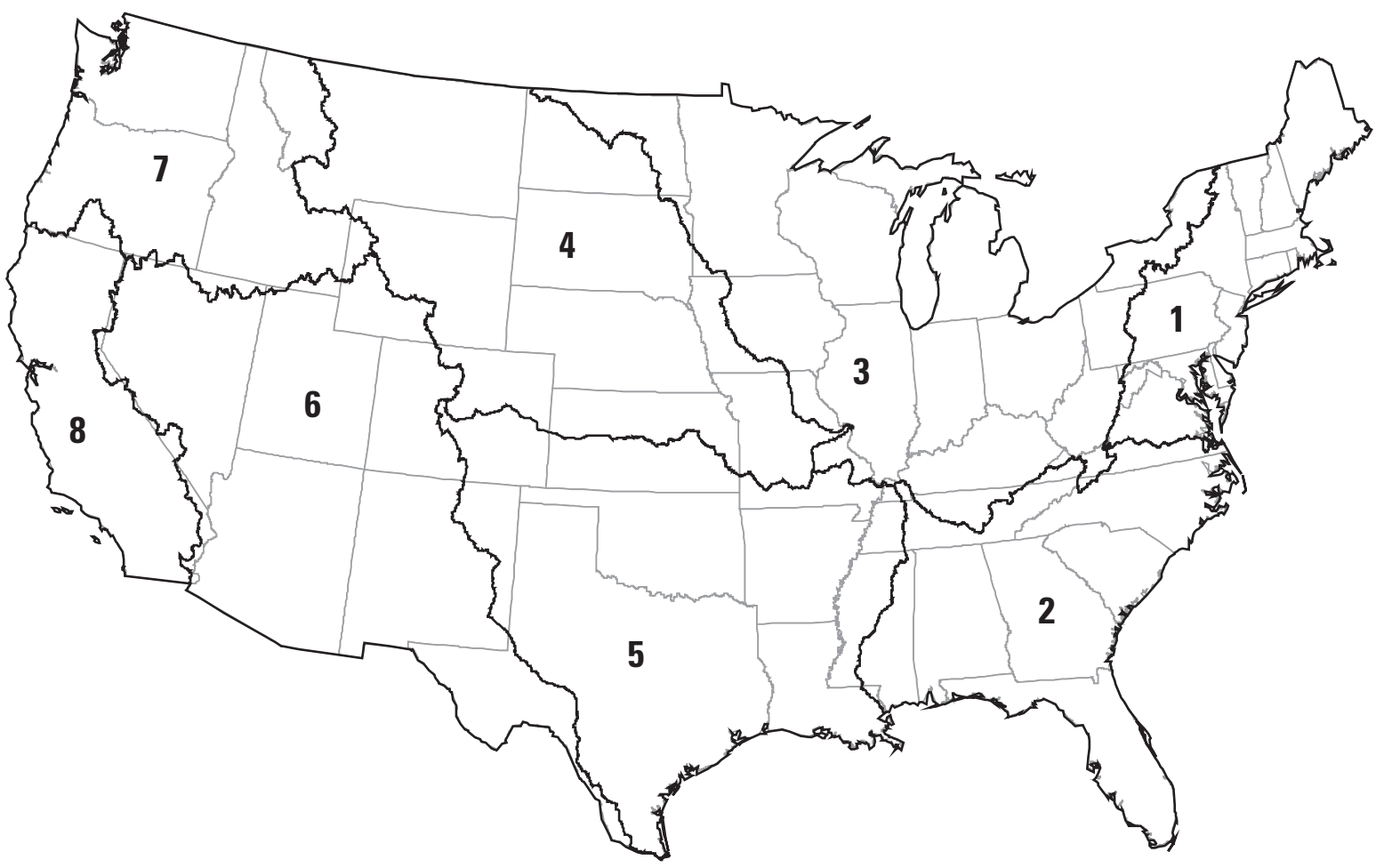

EXPLANATION

1 - Northeast - New England and Mid-Atlantic Water-Resource Regions

2 - Southeast - South Atlantic-Gulf and Tennessee Water-Resource Regions

3 - Midwest - Upper Mississippi, Ohio, Great Lakes, and Souris-Red-Rainey Water-Resource Regions

4 - Northern Plains - Missouri Water-Resource Region

5 - Southern Plains - Lower Mississippi, Arkansas-White-Red, and Texas-Gulf Water-Resource Regions

6 - Southwest - Rio Grande, Upper Colorado, Lower Colorado, and Great Basin Water-Resource Regions

7 - Northwest - Pacific Northwest Water-Resource Region

8 - California - California Water-Resource Region

Figure 3. Areas of the continental United States, defined on the basis of water-source regions, as used in the report.

concentrations were scattered from the Northeast through the Southwest and California (fig. 4B). Many of the sites with high concentrations were downstream from wastewater-treatment plants (WWTPs), which provide an additional nitrogen input. The potential effect of WWTPs is especially large in the arid West, where WWTP discharge can be the primary source of water to urban streams during parts of the year. Selection of NAWQA urban sites was intended to avoid effects of major WWTPs and other point sources, but in some locations this was not feasible.

At sites downstream from relatively undeveloped watersheds, total nitrogen concentrations generally were low (fig. 4C). Medium-range concentrations in the Northeast and in eastern parts of the Midwest were in areas of greater atmo- spheric nitrogen deposition (Ruddy and others, 2006). High concentrations in the Southwest were at sites with greater loads of suspended sediment. NAWQA data presented by Mueller and Spahr (2005) show a general association of high sediment concentrations with high concentrations of particulate organic carbon and total Kjeldahl (organic plus ammonia) nitrogen; therefore, the source of high concentrations of total nitrogen at undeveloped sites could be organic material in suspended sediment.

Downstream from large watersheds, the range of total nitrogen concentrations was broad; however, some regional patterns are evident (fig. 4D). Most of the high concentrations were in the Midwest, where agricultural influence is the greatest. Sites with low concentration are scattered but were 


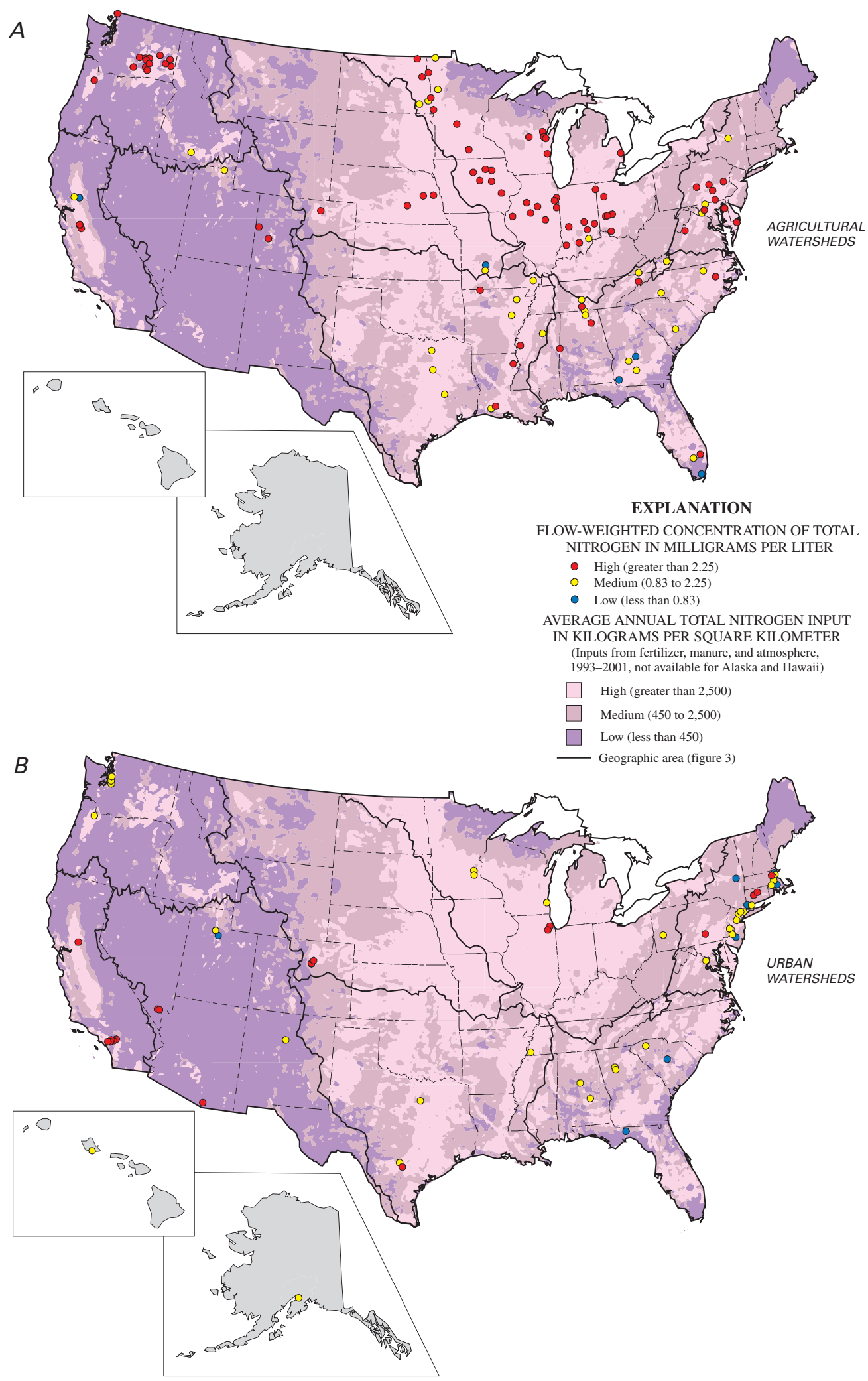

Figure 4. Flow-weighted concentrations of total nitrogen from agricultural, urban, undeveloped, and large watersheds. 


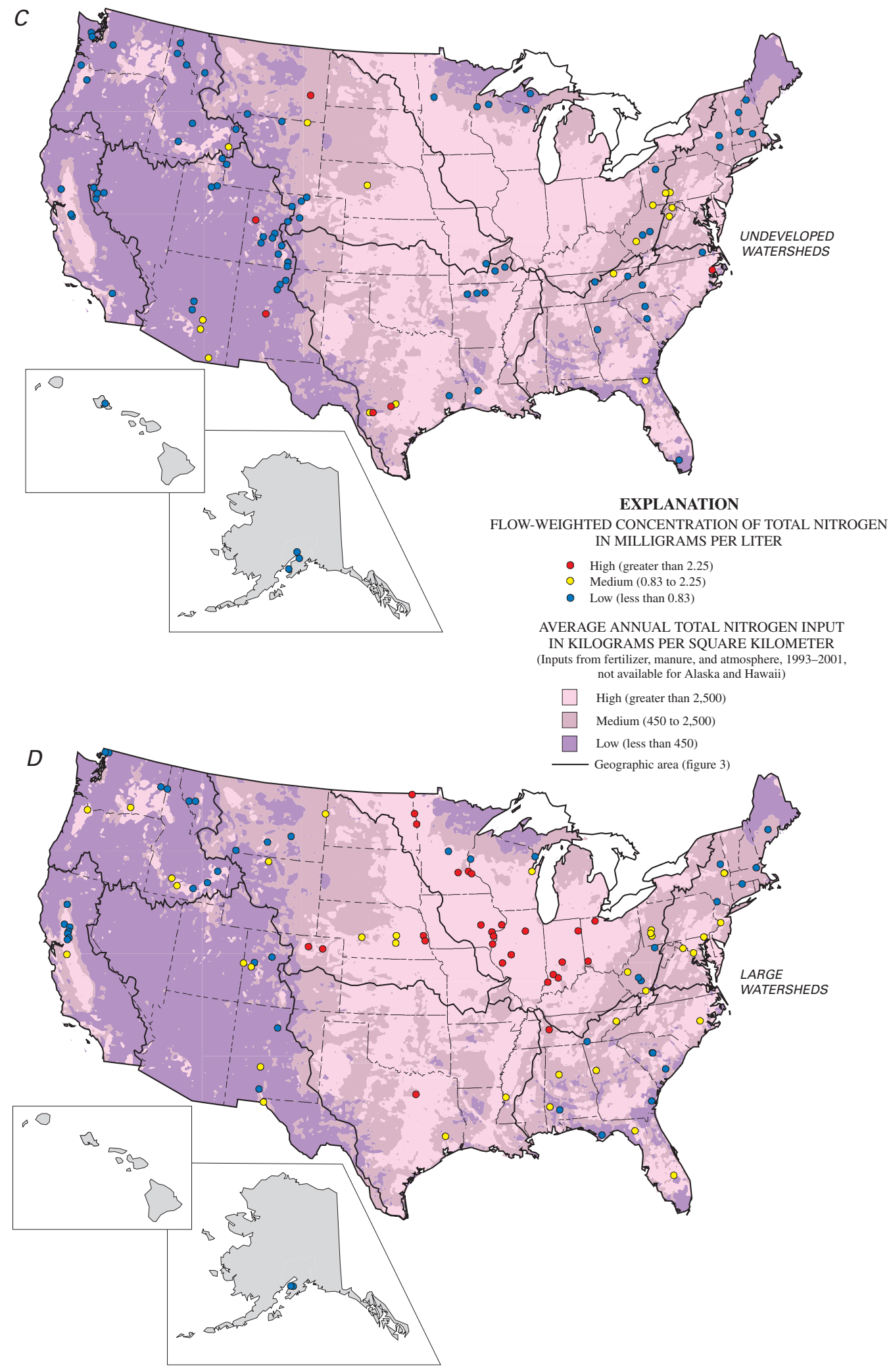

Figure 4. Flow-weighted concentrations of total nitrogen from agricultural, urban, undeveloped, and large watersheds-Continued. 
more common in the Northern Plains, Southwest, Northwest, California, and Alaska, areas of less urban and agricultural development.

In contrast to this distribution of total nitrogen, concentrations of total phosphorus are relatively lower in agricultural areas (more sites in the medium and low ranges, fig. 5A) and higher in undeveloped areas (more sites in the high and medium ranges, fig. 5C). This pattern is particularly strong among agricultural sites in the Northeast, central Midwest, and Northwest and among undeveloped sites in the Northern Plains, Southwest, and California. The primary exceptions are for agricultural sites in the eastern part of the Southern Plains and the northern part of the Midwest, where total phosphorus concentrations are within the high range at most sites. Differences between the distributions of total nitrogen and total phosphorus likely are a result of differences in sources and transport to streams. Nitrogen is more heavily applied in fertilizers, so the input in agricultural areas is relatively greater than for phosphorus. Also, inorganic forms of nitrogen, principally ammonia and nitrate, are very soluble; therefore, they move readily to subsurface drains and ground water, and eventually to streams. Phosphorus compounds are less soluble and attach to soil particles, especially clays. They are more easily transported through coarse-grained soils or by erosion. Thus, phosphorus transport is low in many agricultural areas, where soils are more fine grained and erosion is controlled, but high in association with high suspended-sediment concentrations that can occur in some undeveloped areas, particularly in the Northern Plains and Southwest. Phosphorus has a natural geologic source in many areas of the Nation (Shacklette and others, 1971), so high concentrations can occur downstream from watersheds that have little anthropogenic input.

Downstream from urban areas, concentrations of total phosphorus generally are in the high range (fig. $5 B$ ). This is not surprising because urban sources, such as sewage effluent and septic-system drainage (in areas of lower population density), are major sources of orthophosphate. Other nonpoint sources of phosphorus in urban areas include runoff from lawns and construction sites (Carpenter and others, 1998). High concentrations of total phosphorus at urban sites are more common than high concentrations of total nitrogen through large parts of the Southeast, Southwest, and Hawaii.

At sites downstream from large watersheds, the distribution of total phosphorus concentrations reflects the same differences with respect to total nitrogen as seen for smaller watersheds. Concentrations in the high range are more broadly distributed, though still confined primarily to the Central United States. In comparison to total nitrogen, more total phosphorus concentrations are in the medium or high range in the Northern Plains, Southwest, and California. This difference in distributions is consistent with regional differences in nutrient transport to streams. More streams in the Western United States are likely to have high concentrations of suspended sediment, which is associated with phosphorus transport.
Annual yields (mass per unit area) of total nitrogen and total phosphorus in streamflow from the NAWQA watersheds are shown in figures 6 and 7. In comparison to concentrations, the yields of both constituents in all land-use areas were in relatively higher ranges in much of the humid area of the Eastern United States (Northeast, Southeast, and Midwest) plus the coastal Northwest and Alaska. In contrast, yields were in relatively lower ranges than concentration for watersheds in the semiarid to arid areas of the interior West (Northern Plains, Southwest, and the inland Northwest). This distribution reflects the importance of streamflow. The most striking regional pattern is for total nitrogen yield from large watersheds (fig. $6 D$ ). Yields are medium to high for almost all watersheds in the Eastern United States but are low for almost all watersheds in the West. Yields from watersheds along the West Coast, including Alaska, generally are in the medium to high ranges. This distribution corresponds to patterns of input and streamflow, both of which are relatively lower in the West than in the Eastern United States.

In summary, the geographic distribution of nutrient concentrations and yields depends on regionally variable sources and transport mechanisms, such as drainage, erosion, and runoff. Sources in agricultural areas include fertilizer application and manure from livestock; in urban areas, sources include fertilizer application on lawns, runoff from construction sites, and septic effluent. Atmospheric deposition of nitrogen affects all areas but varies regionally. Nutrient transport in agricultural areas is affected by artificial drainage and irrigation, both of which are more common in particular geographic regions. Soil texture, erosion, and sediment movement also affect transport of some nutrient constituents, particularly total phosphorus.

\section{Seasonal Distribution of Nutrient Concentrations and Streamflow}

In addition to geographic variation, nutrient concentrations in streams and rivers commonly vary by season of the year. In many locations, this seasonal variation is associated with differences in the amount and sources of streamflow. Typically, during seasons of high streamflow, due to rainfall or snowmelt, dissolved nutrient concentrations are significantly different than during seasons of low streamflow fed by base flow from ground water. Other factors, such as point sources or irrigation, can have a seasonally varying effect on nutrient concentrations. Seasonal variations in nutrient concentrations were determined for each NAWQA sampling site and were used to identify regional patterns in the occurrence of high and low concentrations.

Seasonal cycles in temperature and precipitation vary throughout the Nation, depending in part on latitude and altitude; however, for this report a consistent monthly definition was used to identify seasons. Autumn was defined as August through October, which corresponds to a base-flow period in many parts of the Nation. Winter was then November through January, spring was February through April, and summer was 


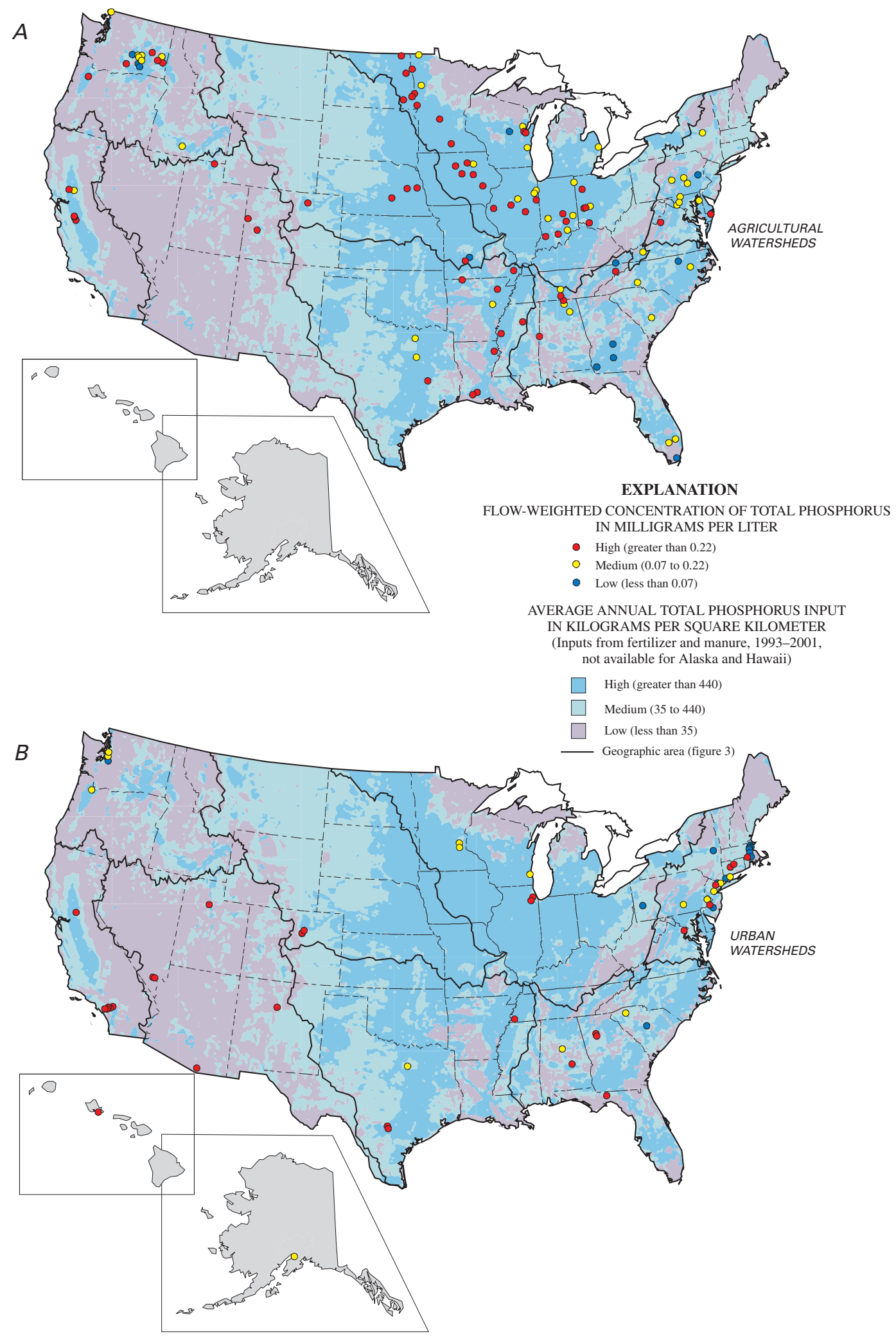

Figure 5. Flow-weighted concentrations of total phosphorus from agricultural, urban, undeveloped, and large watersheds. 


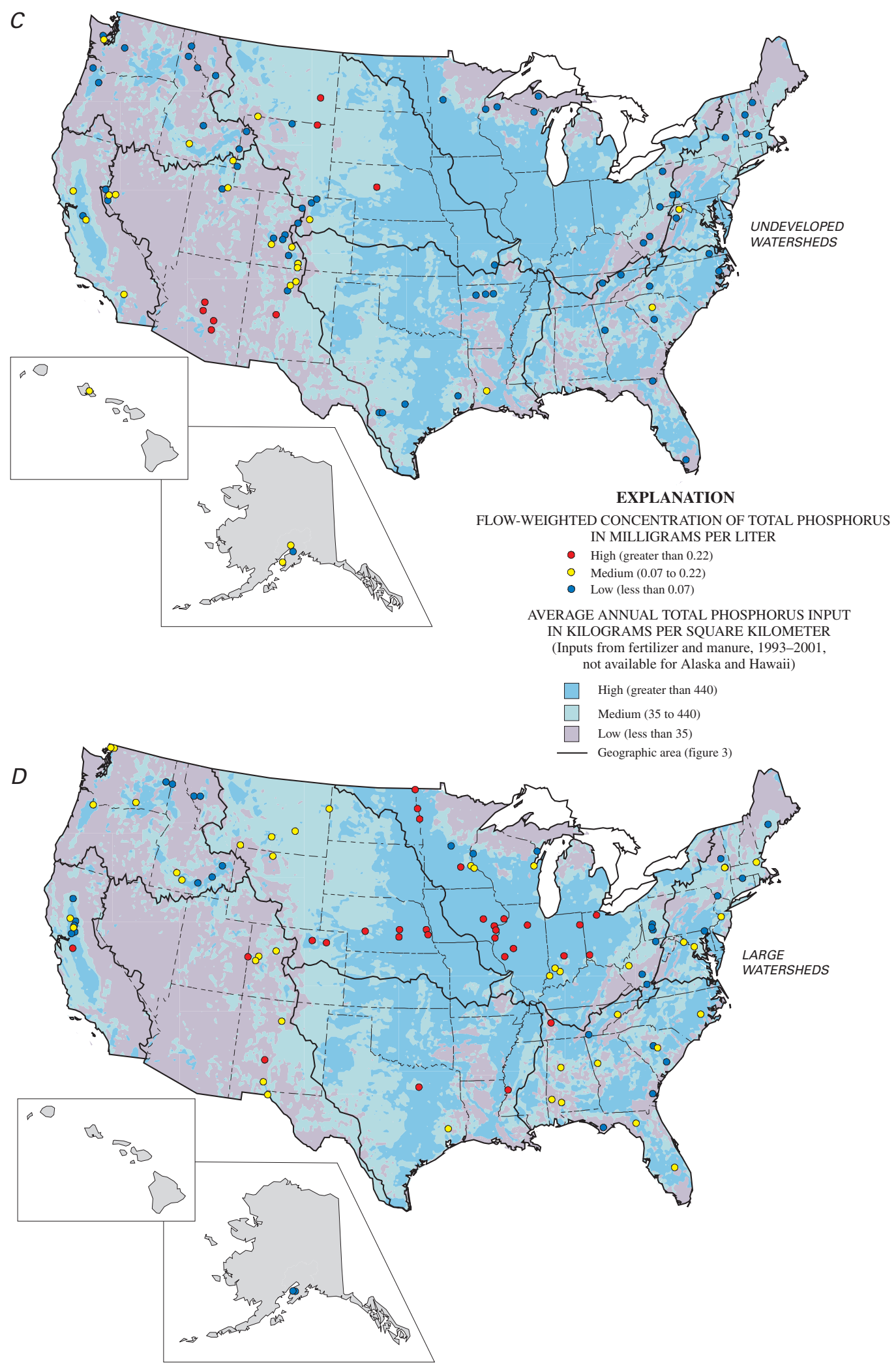

Figure 5. Flow-weighted concentrations of total phosphorus from agricultural, urban, undeveloped, and large watersheds-Continued. 


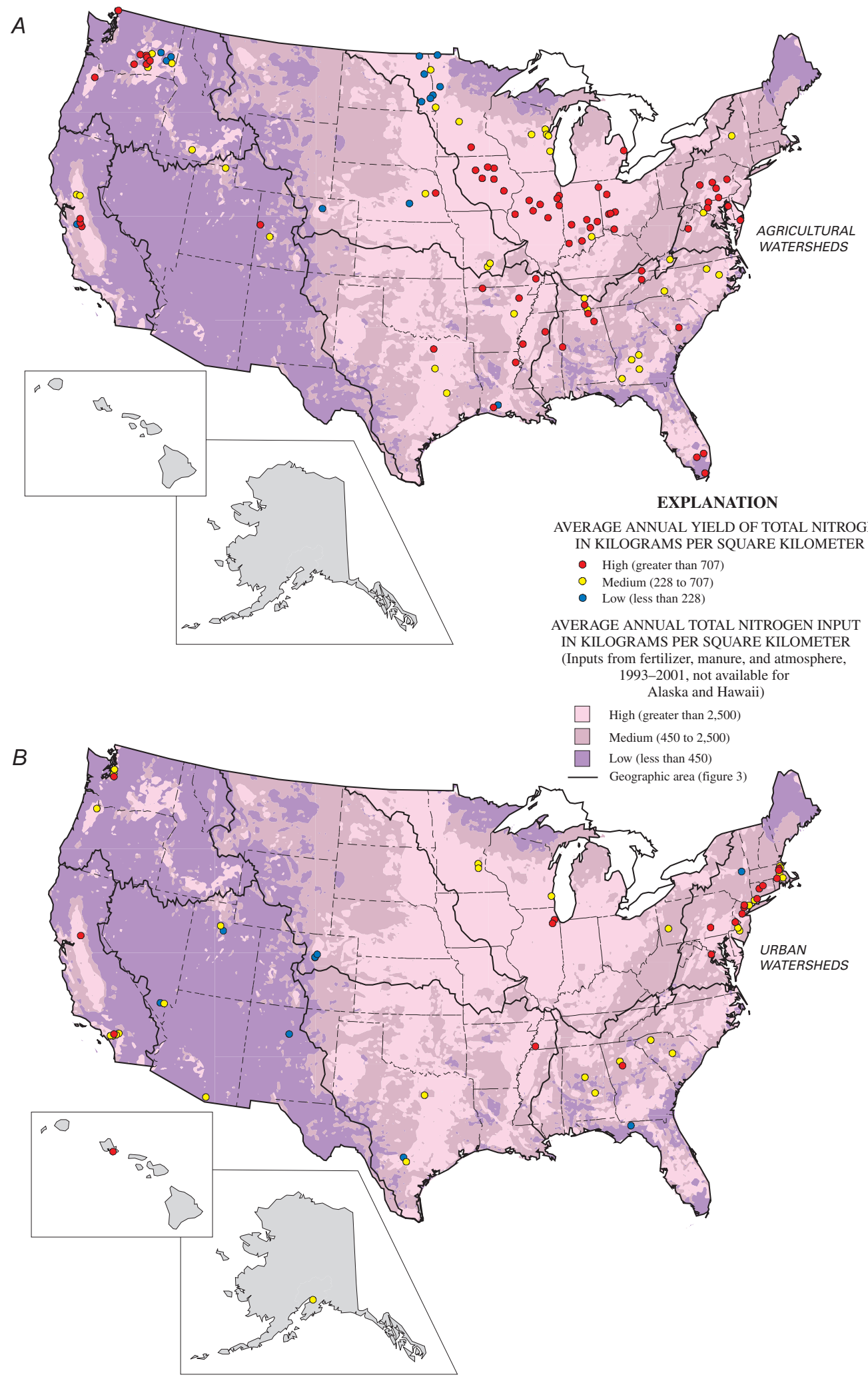

Figure 6. Annual yield of total nitrogen from agricultural, urban, undeveloped, and large watersheds. 
C

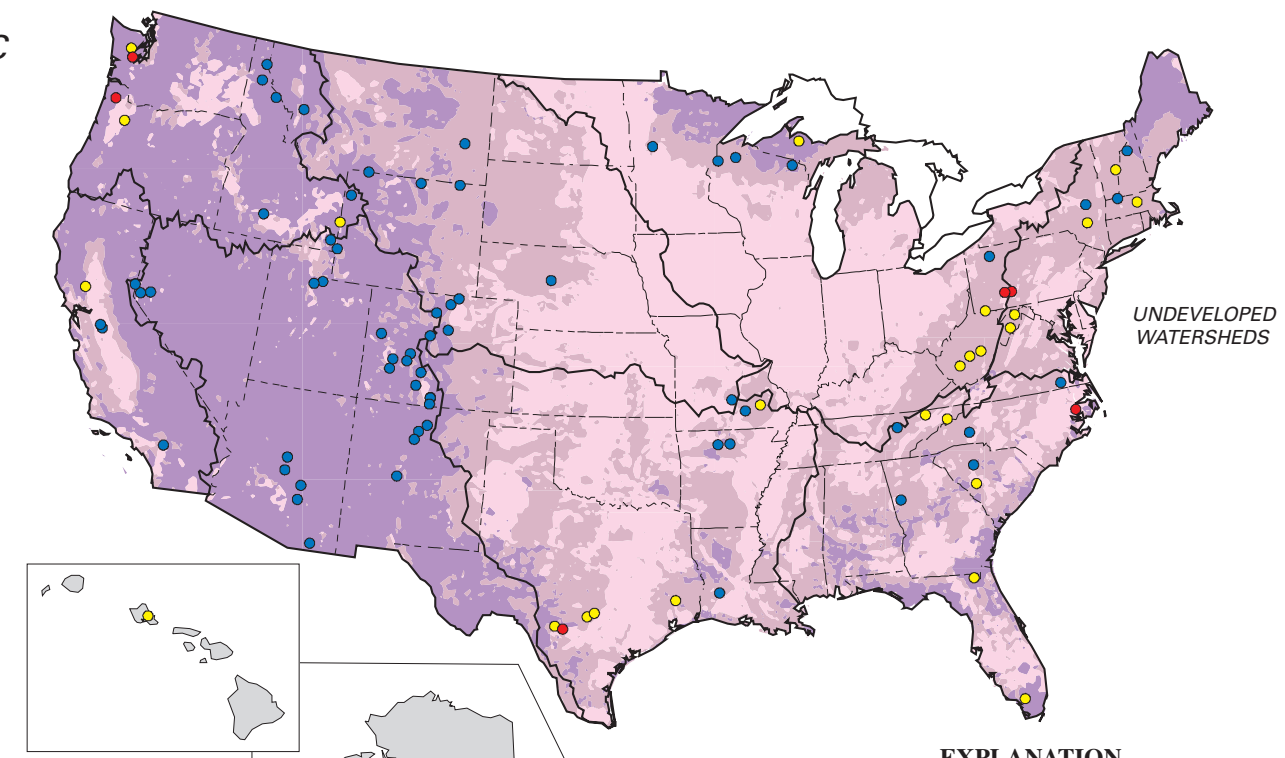
IN KILOGRAMS PER SQUARE KILOMETER

- High (greater than 707)

- Medium (228 to 707 )

AVERAGE ANNUAL TOTAL NITROGEN INPUT IN KILOGRAMS PER SQUARE KILOMETER

(Inputs from fertilizer, manure, and atmosphere, 1993-2001, not available for Alaska and Hawaii)

High (greater than 2,500)

$D$

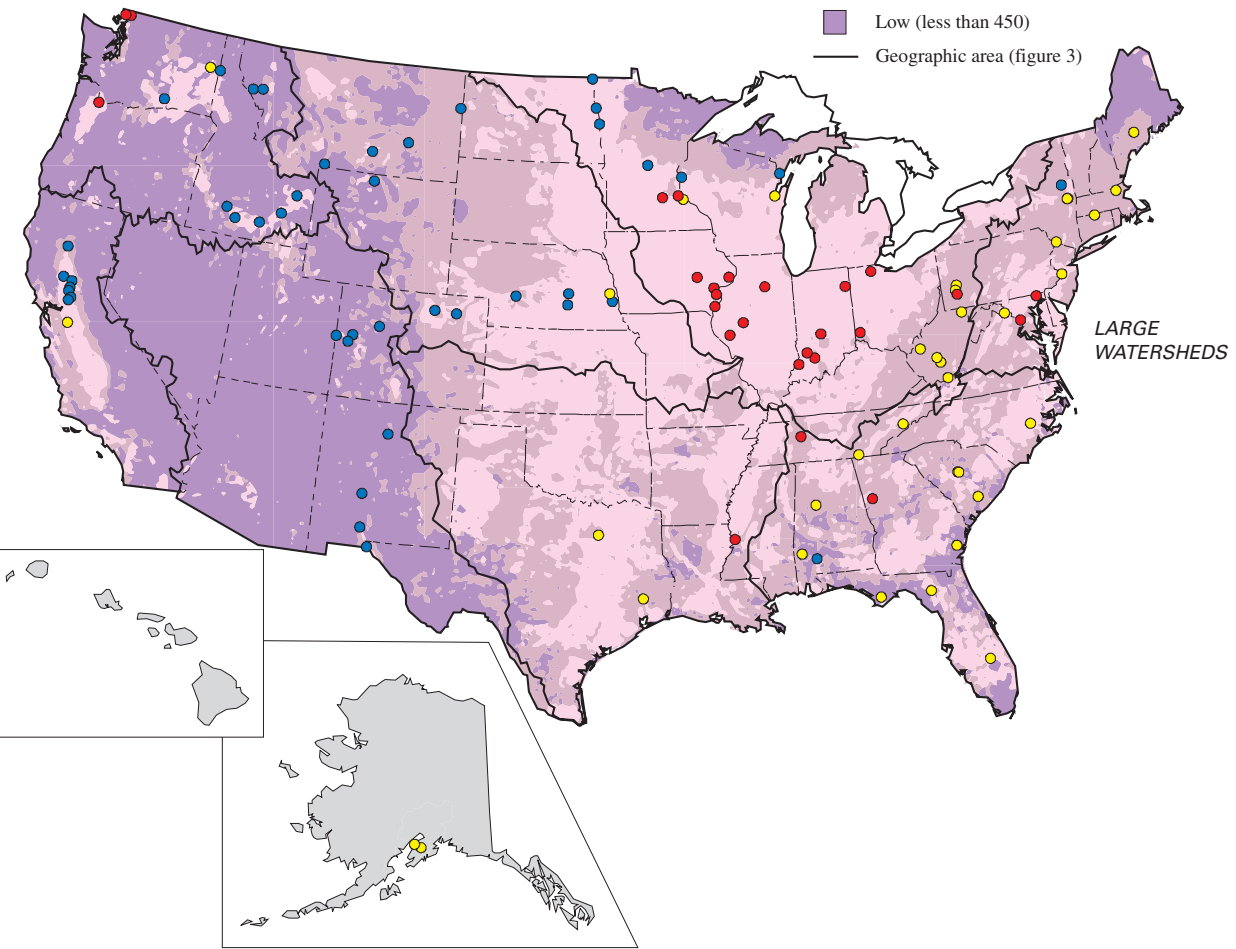

Figure 6. Annual yield of total nitrogen from agricultural, urban, undeveloped, and large watershedsContinued. 


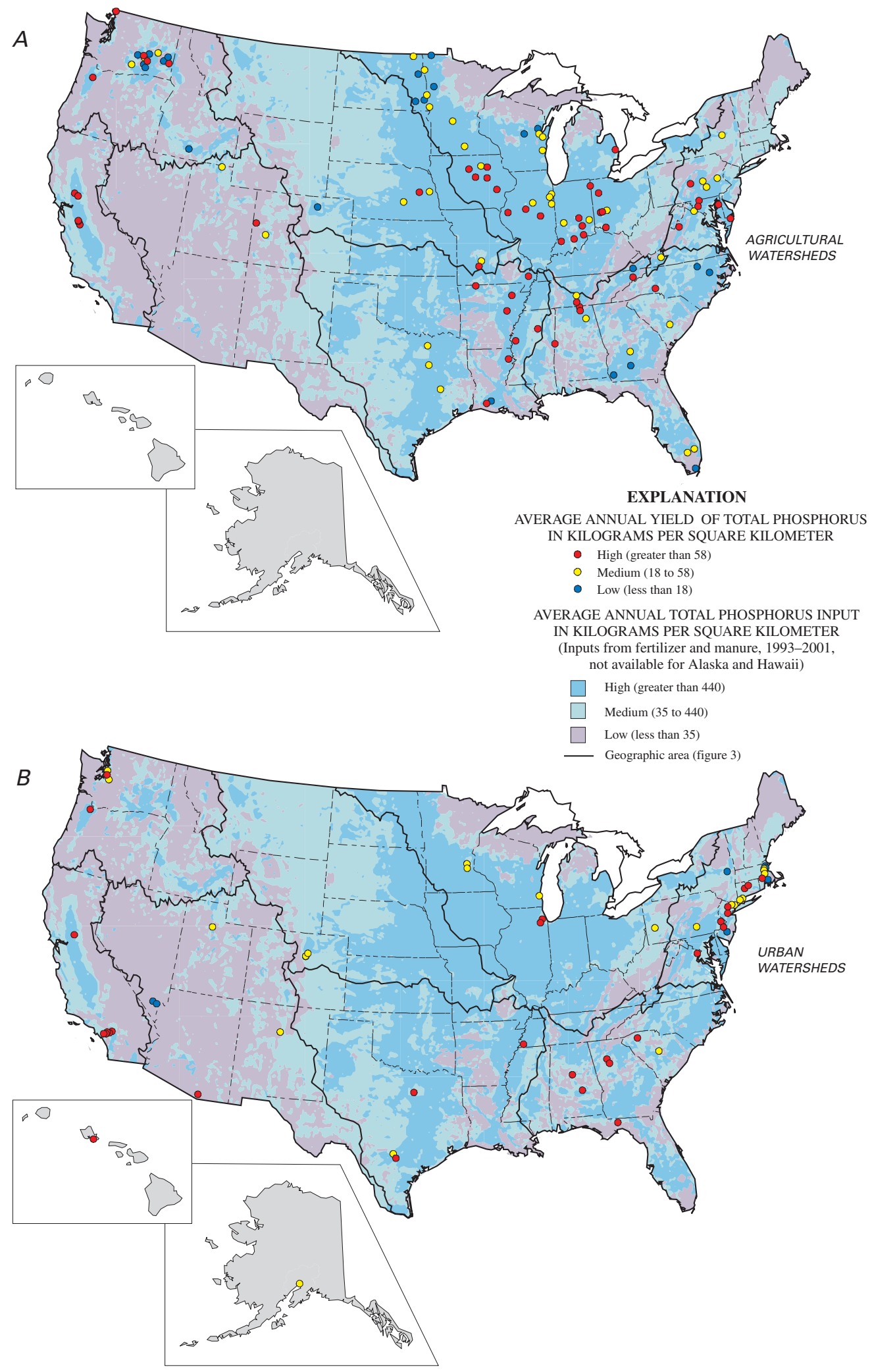

Figure 7. Annual yield of total phosphorus from agricultural, urban, undeveloped, and large watersheds. 


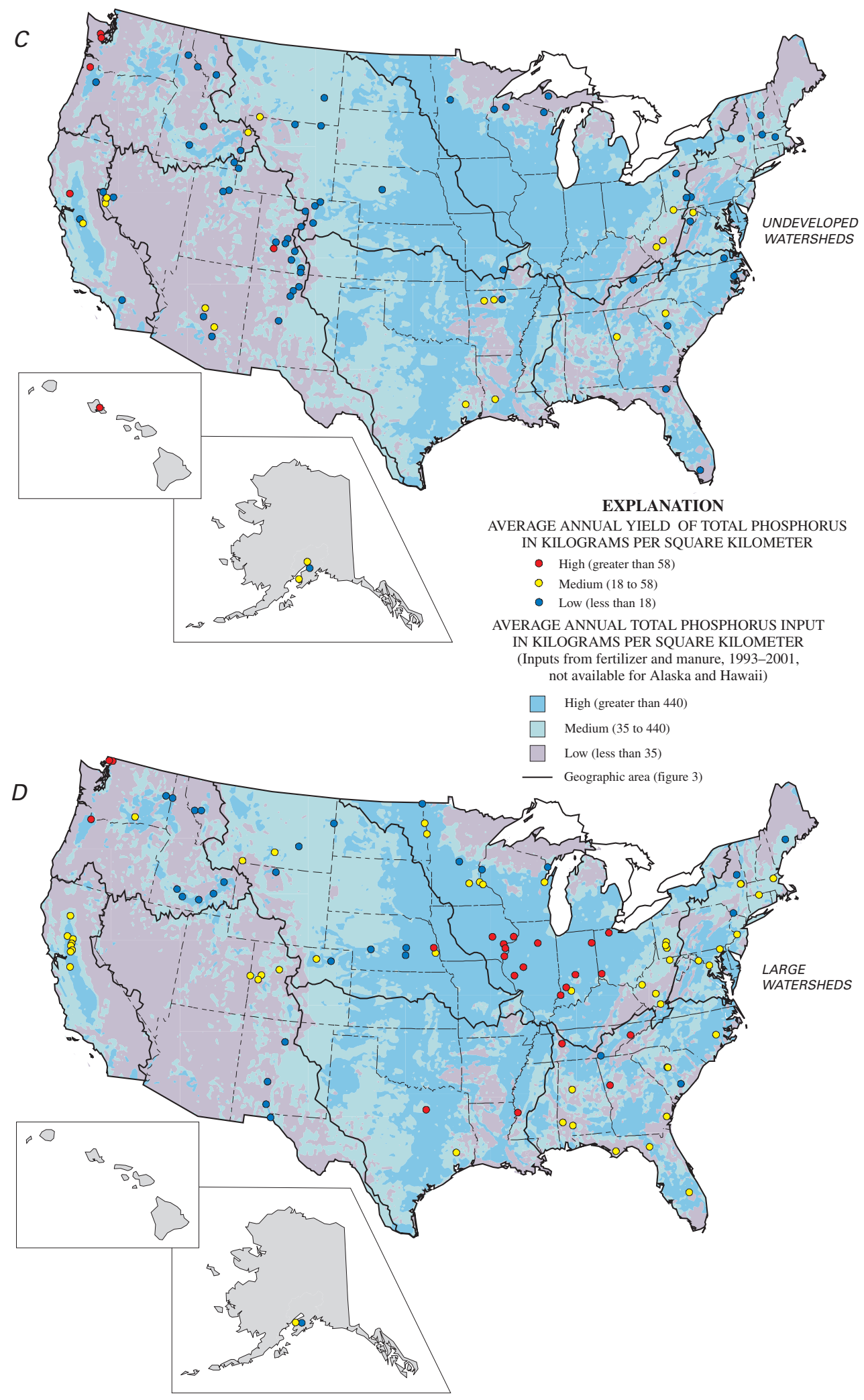

Figure 7. Annual yield of total phosphorus from agricultural, urban, undeveloped, and large watersheds-Continued. 
May through July, which includes the time of snowmelt runoff in northern latitudes. For each site, daily streamflow and estimates of daily nutrient concentrations, from load-model results, were determined for one or more complete water years during the high-intensity sampling period. Streamflow and concentrations for each nutrient constituent at each individual site were then ranked from lowest to highest, and the ranks were grouped by the defined seasons. Differences in the distributions of data among seasons were determined by analysis of variance (ANOVA) on the grouped ranks. If data for a particular parameter (streamflow or nutrient concentrations) at a specific site were significantly higher in one season, that season was identified as the "high" season for that parameter at that site. "Low" seasons were similarly identified. If no single season was significantly higher or lower, then the high or low season for that parameter at that site was considered to be mixed. If there were no significant differences in parameter values among any seasons at a site, that parameter was considered to have no seasonal distribution at that site.

Regional patterns in seasonally high and low streamflow are shown in figure 8. Low flows occur during the defined autumn season (August-October) at many sites. A broad area of spring (February-April) high flows and autumn low flows occurs in the Eastern United States (Northeast; Southeast, except southern Florida; much of the Midwest; and Southern Plains, except south Texas). Similar flow conditions occur at many sites along the West Coast (California and the coastal Northwest). In contrast, at sites over a broad area of the interior West (Northern Plains; Southwest, except Arizona and southern Nevada; and the inland Northwest, except eastern Washington) flows are high in the summer (May-July) and low in various times during autumn through spring. In general, this area receives less rainfall than either the Eastern United States or the West Coast, and high flow at many locations results from snowmelt runoff and irrigation return flow. In addition to these three large areas, several smaller areas have more localized patterns of high and low flow. In the northern Midwest, high flows generally occur in the summer, as in the interior West, but low flows are more common in the winter (November-January), when streams can be covered with ice. In Arizona and southern Nevada, seasonality of streamflow is mixed, but high flows are most common in the spring and, opposite to the rest of the Southwest, low flows are more common in the summer. This is the most arid area of the United States, and flow in many streams is affected or dominated by point-source effluent. Other areas, including southern Florida, southern Texas, eastern Washington, Alaska, and Hawaii, have varied streamflow seasons.

Seasonally high and low concentrations of total nitrogen and total phosphorus (figs. 9 and 10) have less distinct regional patterns, but to some extent follow the patterns described for streamflow. In the Eastern United States, concentrations of total nitrogen generally are high in the spring and low in the autumn, similar to streamflow. In contrast, the seasonal variation of total phosphorus is generally opposite to streamflow; high concentrations are more common in summer and autumn, and low concentrations are more common in the spring. This pattern is reversed in the interior West. Seasonal concentrations of total phosphorus, like streamflow, generally are high in the summer and low during the autumn or winter. Nitrogen concentrations at sites in this area generally are high in the winter or spring and low during the summer or autumn. Thus, a major difference between the humid Eastern United States and the more arid interior West is the seasonality of nutrient concentrations in relation to streamflow. This pattern indicates that mobilization and transport of nutrients to streams during high flow favors nitrogen in the Eastern United States and phosphorus in the interior West. One possible explanation for this effect is that soluble nitrogen compounds are transported more by rainfall runoff in the Eastern United States, but more by irrigation return flows in the interior West. Rainfall runoff is obviously greater during the high-flow season, but return flows are greater during the low-flow season when irrigation applications are larger. Phosphorus compounds are less soluble and transported more readily by erosion, which is more likely during high-flow seasons and is more common in the semiarid to arid interior West than in the Eastern United States.

Along the West Coast, high concentrations of total nitrogen and total phosphorus primarily have mixed seasonality but are common in the winter and spring (figs. 9 and 10). Streamflow also is high predominantly in mixed seasons or in the spring. Similarly, low concentrations of both nutrients are common in summer and autumn, whereas low streamflow occurs predominantly in autumn. Thus, in these areas, the seasonal variations of nitrogen and phosphorus are directly associated with seasonal variations in streamflow. The West Coast and northern Midwest are similar to the Eastern United States in seasonality of total nitrogen but are similar to the interior West in seasonality of total phosphorus. Mobilization and transport of both nutrients occurs primarily during the season of high streamflow.

In Arizona and southern Nevada, the seasonal variation in high concentrations of phosphorus is similar to that for streamflow. Thus, transport mechanisms for phosphorus in this area and in the interior West might have some similarities, though the predominant high-flow and low-flow seasons differ between the two areas.

Regional patterns in the seasonality of dissolved nutrient constituents are less distinct than those of total nitrogen and total phosphorus. One reason could be that concentrations of dissolved constituents are affected by point sources at some sites. These sites are more likely to have mixed seasonality if nonpoint sources produce high concentrations during high streamflow and point sources produce high concentrations during low streamflow. For ammonia, which is common in septic effluent, sites with no seasonal distribution are common throughout all regions of the continental United States (fig. 11). In comparison to total nitrogen, seasonally high concentrations of nitrate are more common in winter (fig. 12). The source of high nitrate in the winter could be point sources or ground-water base flow. High flow, which could dilute concentrations from these sources, rarely occurs during the winter 


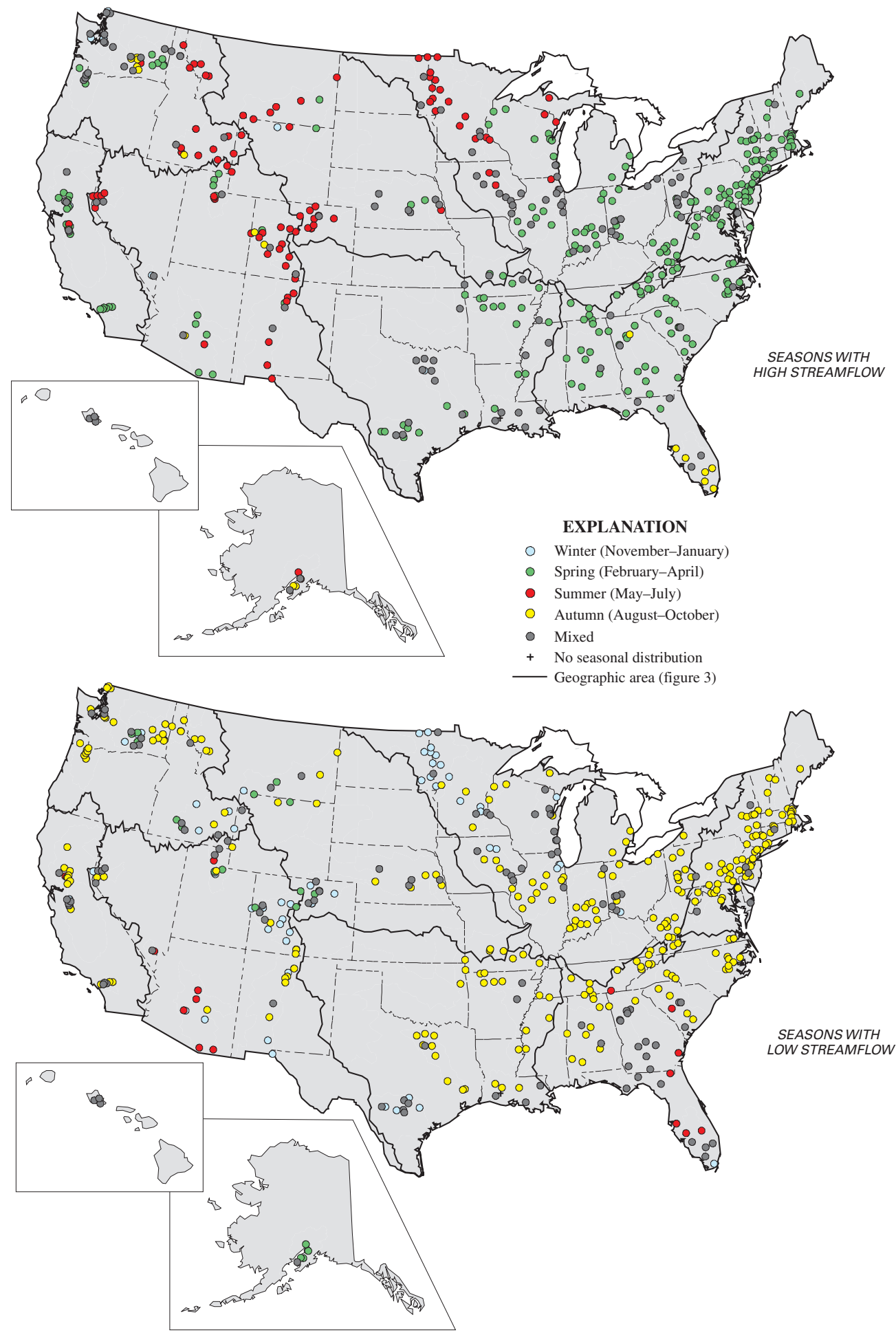

Figure 8. Distribution of high and low seasonal streamflow. 


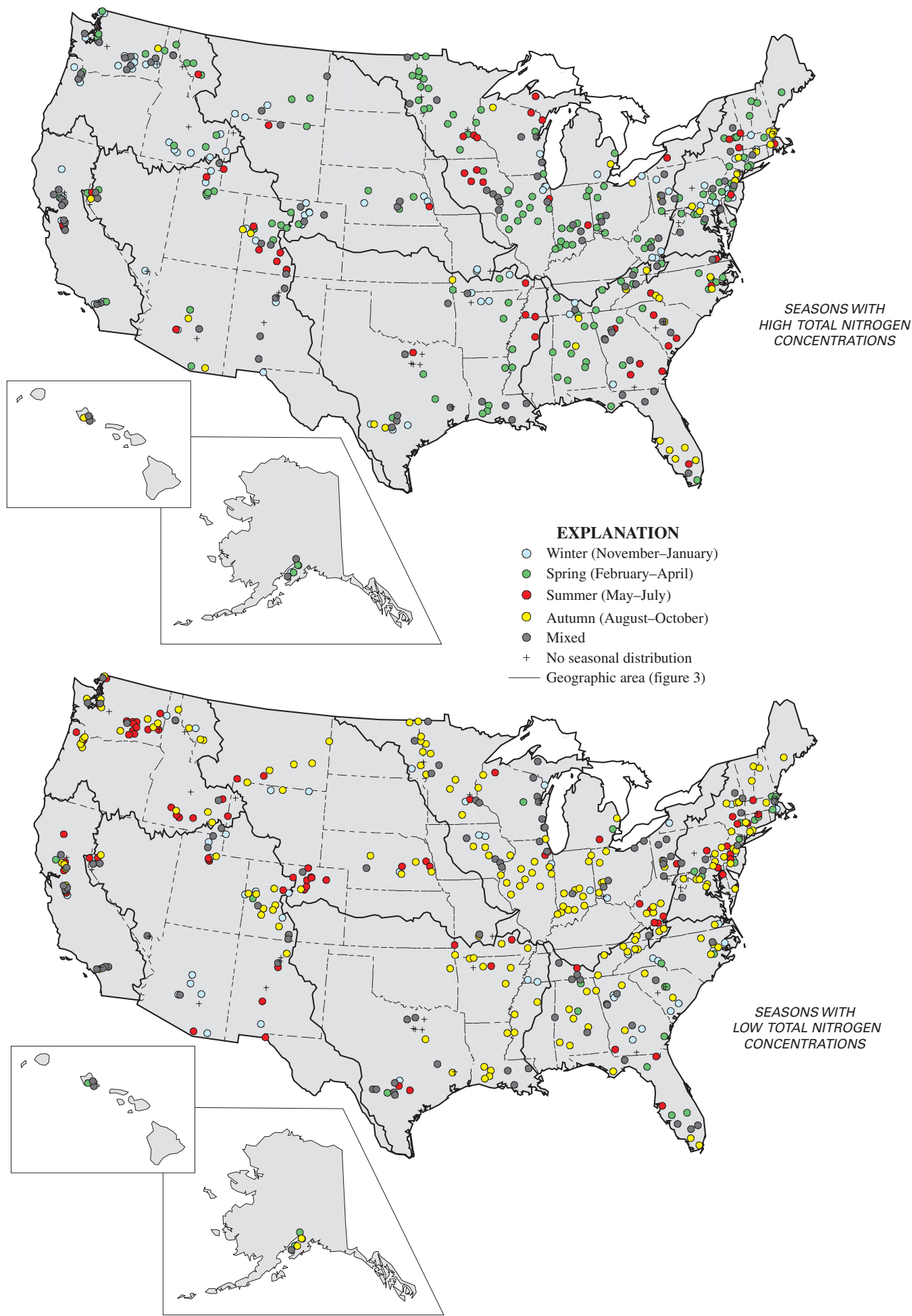

Figure 9. Distribution of high and low seasonal concentrations of total nitrogen. 


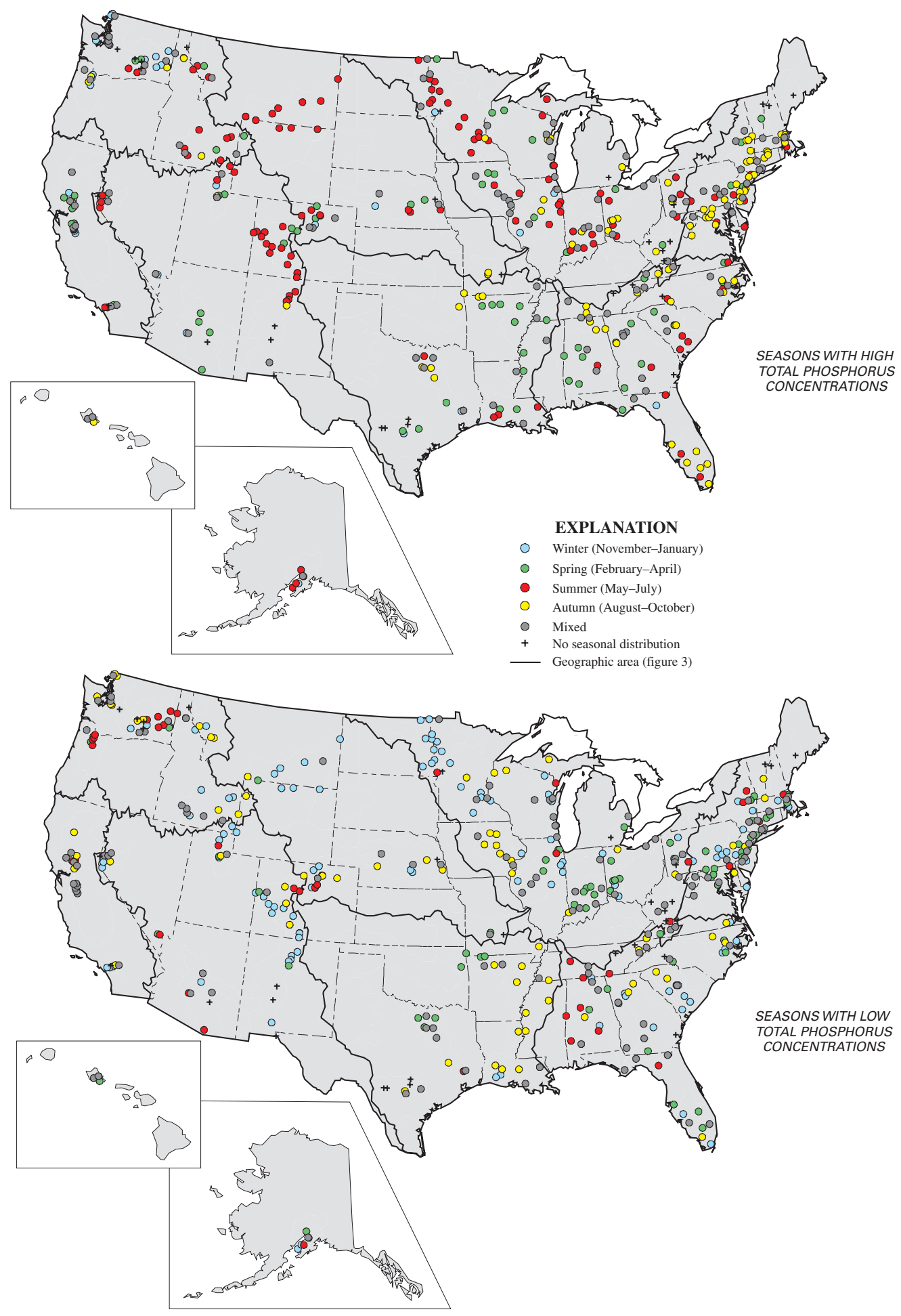

Figure 10. Distribution of high and low seasonal concentrations of total phosphorus. 


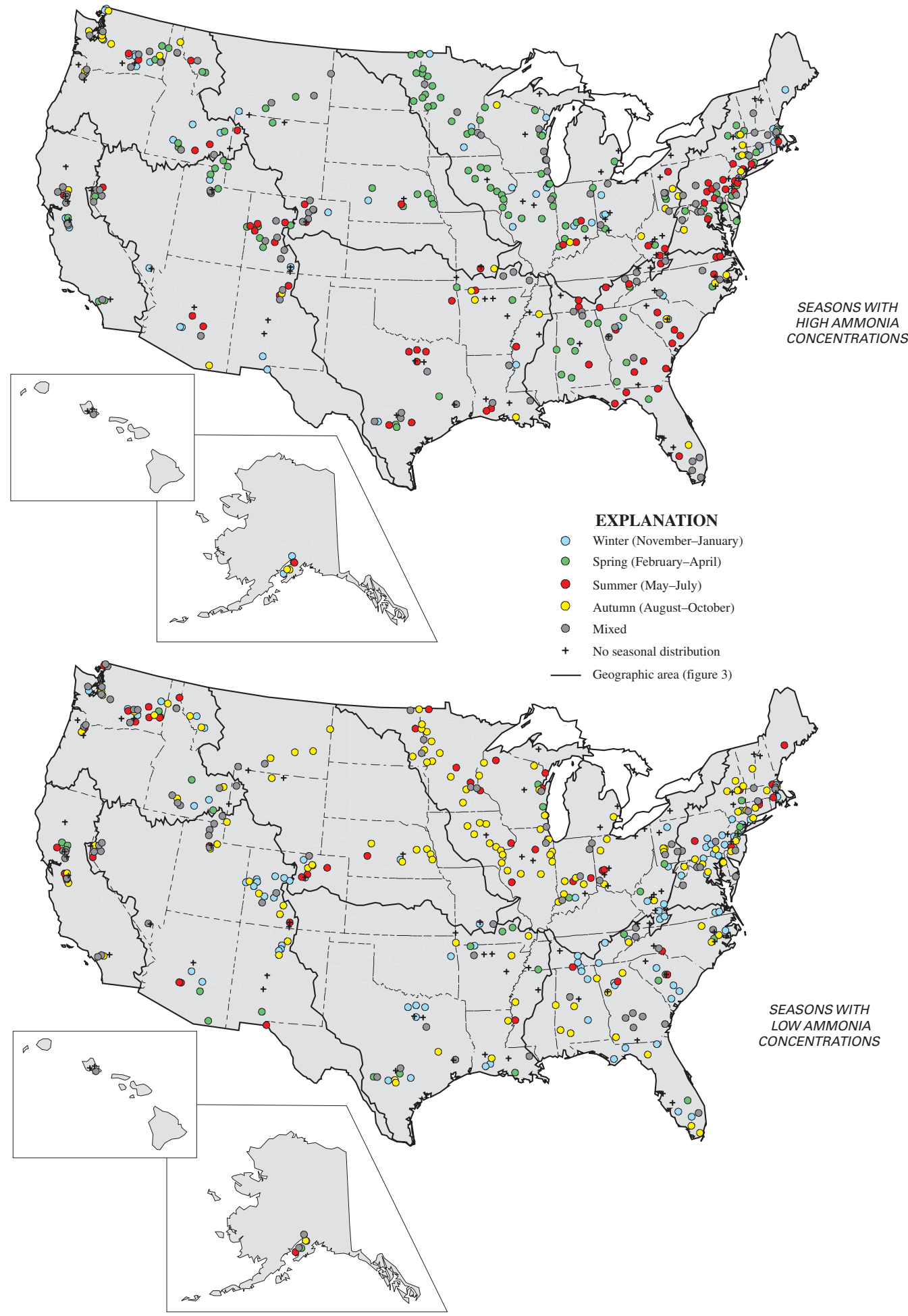

Figure 11. Distribution of high and low seasonal concentrations of ammonia. 


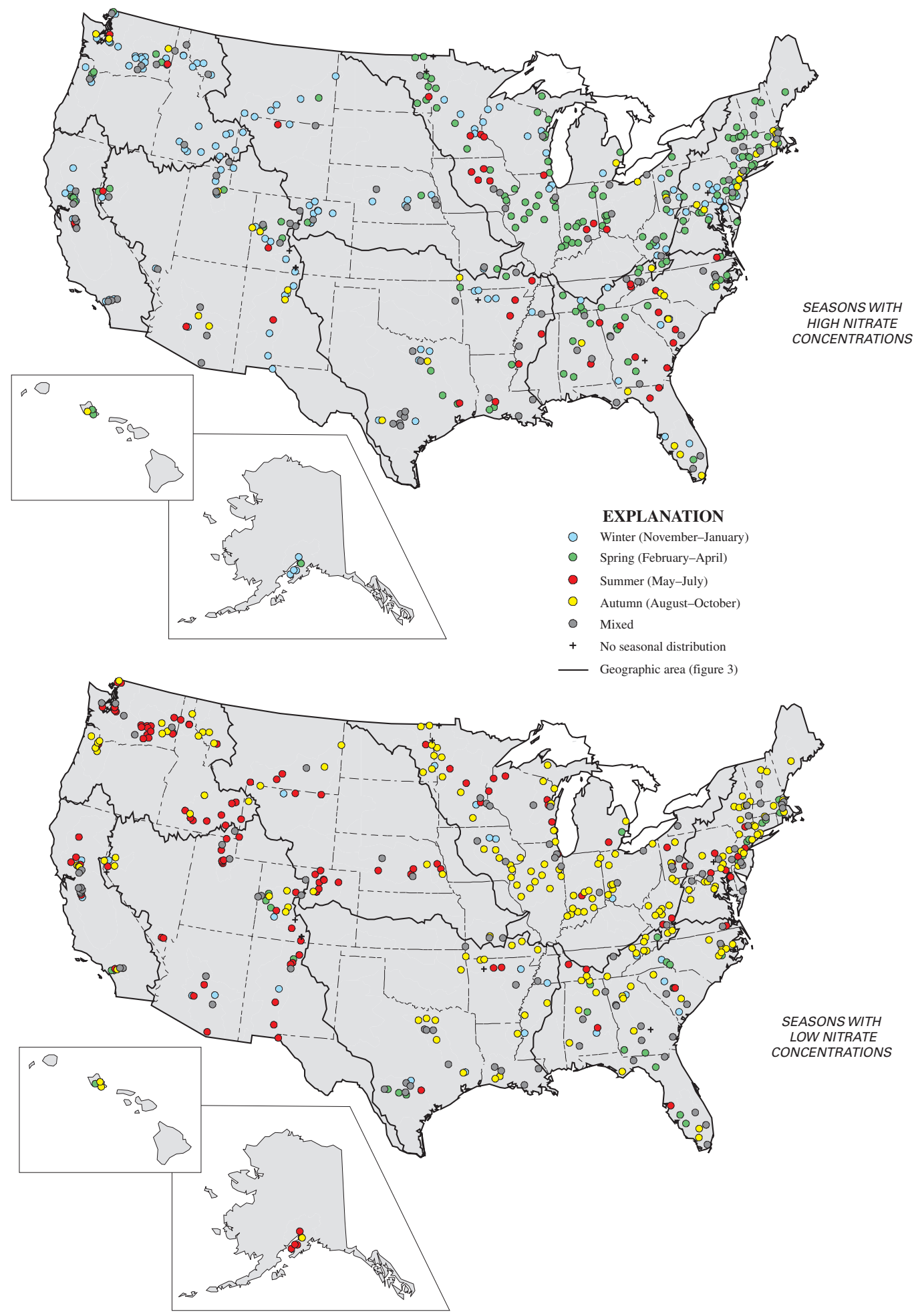

Figure 12. Distribution of high and low seasonal concentrations of nitrate. 
season. In addition, algal uptake of dissolved nutrients is lower in the winter. Low concentrations of nitrate generally occur in the same seasons as low concentrations of total nitrogen. The seasonality of orthophosphate (fig. 13) in relation to total phosphorus (fig. 10) has a similar pattern, but more regional variation. High concentrations of orthophosphate in the summer generally occur at fewer sites than high concentrations of total phosphorus, especially in the interior West and the northern Midwest (fig. 13). In these areas, high total phosphorus concentrations are related to high summer streamflow, but high orthophosphate concentrations are more common in low-flow months and in months with less algal uptake. Low orthophosphate concentrations in the Eastern United States are more common during the spring high-flow season than are low concentrations of total phosphorus. High concentrations of orthophosphate in this area are more common during the autumn low-flow season. In all these areas, the source of orthophosphate during low flow could be wastewater-treatment plant point sources or septic-system nonpoint sources.

\section{Relations between Nutrient Distributions and Land Use}

Geographic analysis indicated that land use is a major factor in the distribution of total nitrogen and total phosphorus concentrations and yields in streams and rivers. In this section of the report, investigation of the association between land use and nutrient distributions is expanded. NAWQA sites are categorized on the basis of upstream land use as previously described in the "Ancillary Data" section. In addition, nutrient distributions at relatively undeveloped sites are compared to previously defined background conditions. Finally, nutrient concentrations, yields, and loads are evaluated in relation to a variety of watershed characteristics.

\section{Comparison of Nutrient Concentrations and Yields among Major Land Uses}

Distributions of flow-weighted mean annual concentrations of five nutrient constituents at sites in each of the six land-use categories are plotted in figure 14. Each box plot indicates selected percentiles of the distribution of concentrations for a particular nutrient constituent at sites in a particular land-use category. The central box includes concentrations ranging from the 25 th to the 75 th percentiles; therefore, it incorporates 50 percent of all sites. Together, the two whiskers incorporate another 30 percent of all sites; those with concentrations between the 75 th and 90 th percentiles are in the upper whisker and those with concentrations between the 10th and 25th percentiles are in the lower whisker. The highest and lowest 10 percent of concentrations are not shown. Letters next to the median of each box plot indicate significant differences among distributions of concentration for land-use categories. Because many of the distributions did not appear to be normal and because differences in standard deviation were obvious from variations in spread, nonparametric statistical methods were chosen to test for differences among groups of data. Differences among all land-use categories were tested by using analysis of variance on the ranks of the data (Conover and Iman, 1981). If a significant difference was indicated by this test, differences between individual land-use categories were evaluated by applying Tukey's multiple-comparison test (Helsel and Hirsch, 1992, p. 196) to the rank-transformed data. Box plots identified by the same letter indicate that the distributions are not significantly different. If two letters are listed (for example, BC), the distribution is not significantly different from other distributions identified by either one of those letters (for example, B, C, AB, BC, or CD).

Concentrations of all nutrient constituents at sites downstream from undeveloped areas are significantly less than at all other sites. The 75th percentile for undeveloped sites is less than the 50th percentile for all other land uses for all constituents except total phosphorus. In many cases, the 90th percentile for undeveloped sites is less than the 25th percentiles for agricultural, urban, and mixed land-use sites. Thus, these undeveloped sites, in general, provide an adequate baseline for comparing to potential effects of development at sites downstream from agricultural and urban areas. Although concentrations of total phosphorus are significantly lower at undeveloped sites, they are not as low relative to other land uses as are the concentrations of other nutrient constituents. The likely cause is naturally occurring phosphorus associated with the high suspended-sediment concentration at some undeveloped sites.

Evidence is strong that concentrations of all nutrients increase as development increases. Concentrations of all nutrient constituents at partially developed sites are significantly greater than at undeveloped sites but significantly less than at the more developed agricultural, urban, and mixed land-use sites. Concentrations at agricultural, urban, and mixed landuse sites are not significantly different, except:

- Nitrate is greater at agricultural and mixed land-use sites than at urban sites.

- Total nitrogen is greater at agricultural than at urban sites.

- Orthophosphate is greater at mixed land-use than at urban sites.

Nitrate exceeded the USEPA maximum contaminant level for drinking water $(10 \mathrm{mg} / \mathrm{L}$; U.S. Environmental Protection Agency, 2003) at more than 12 percent (14 of 115) of the agricultural sites, but these are not streams used for public water supplies. Streams at large sites are more likely to represent water available for public supply. Nitrate concentrations exceeded $10 \mathrm{mg} / \mathrm{L}$ at only three (of 105) large sites.

At sites downstream from large watersheds, concentrations of most nutrients are significantly less than at smaller agricultural, urban, and mixed land-use sites. The only exceptions are for nitrate and orthophosphate concentrations, which 


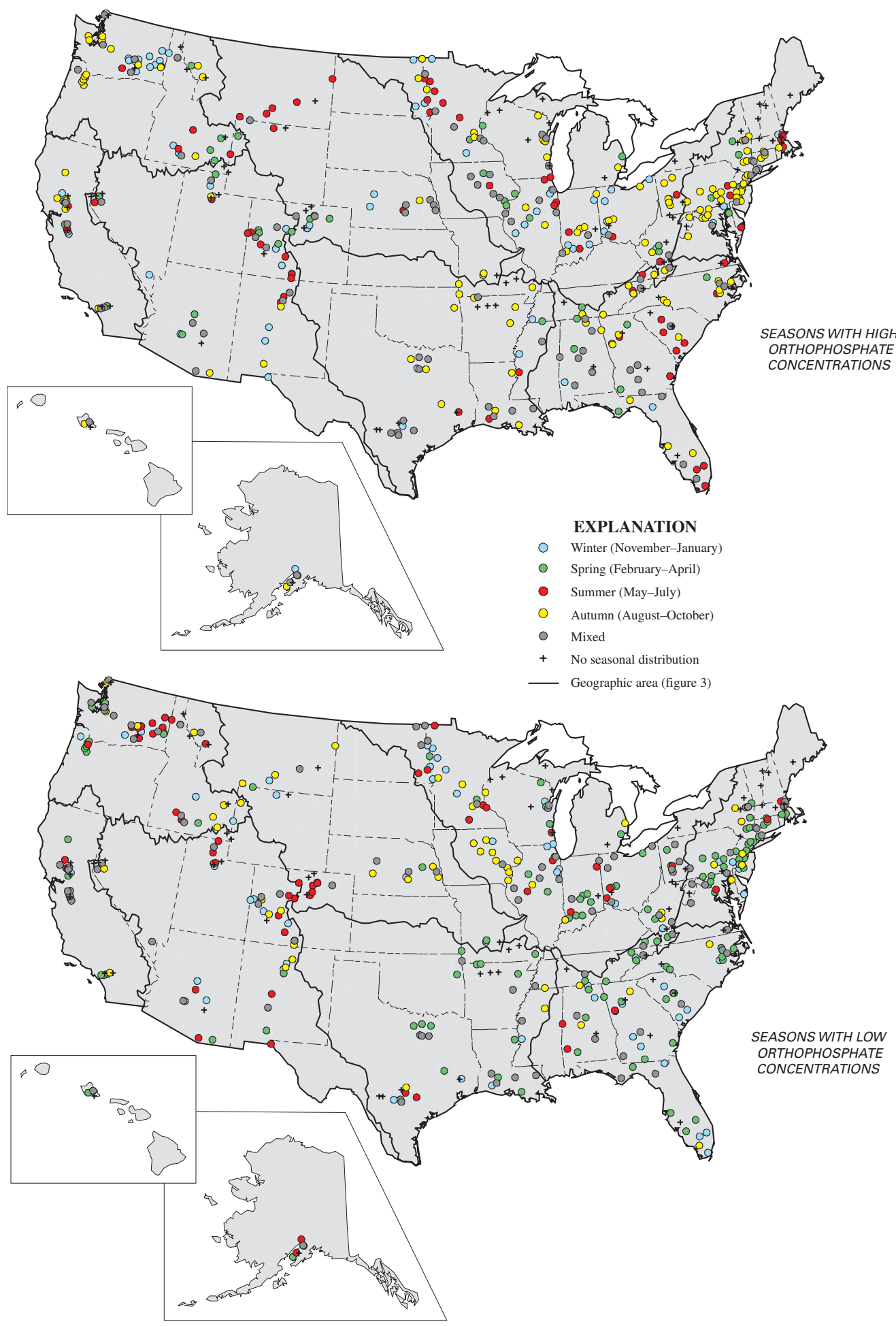

Figure 13. Distribution of high and low seasonal concentrations of orthophosphate. 

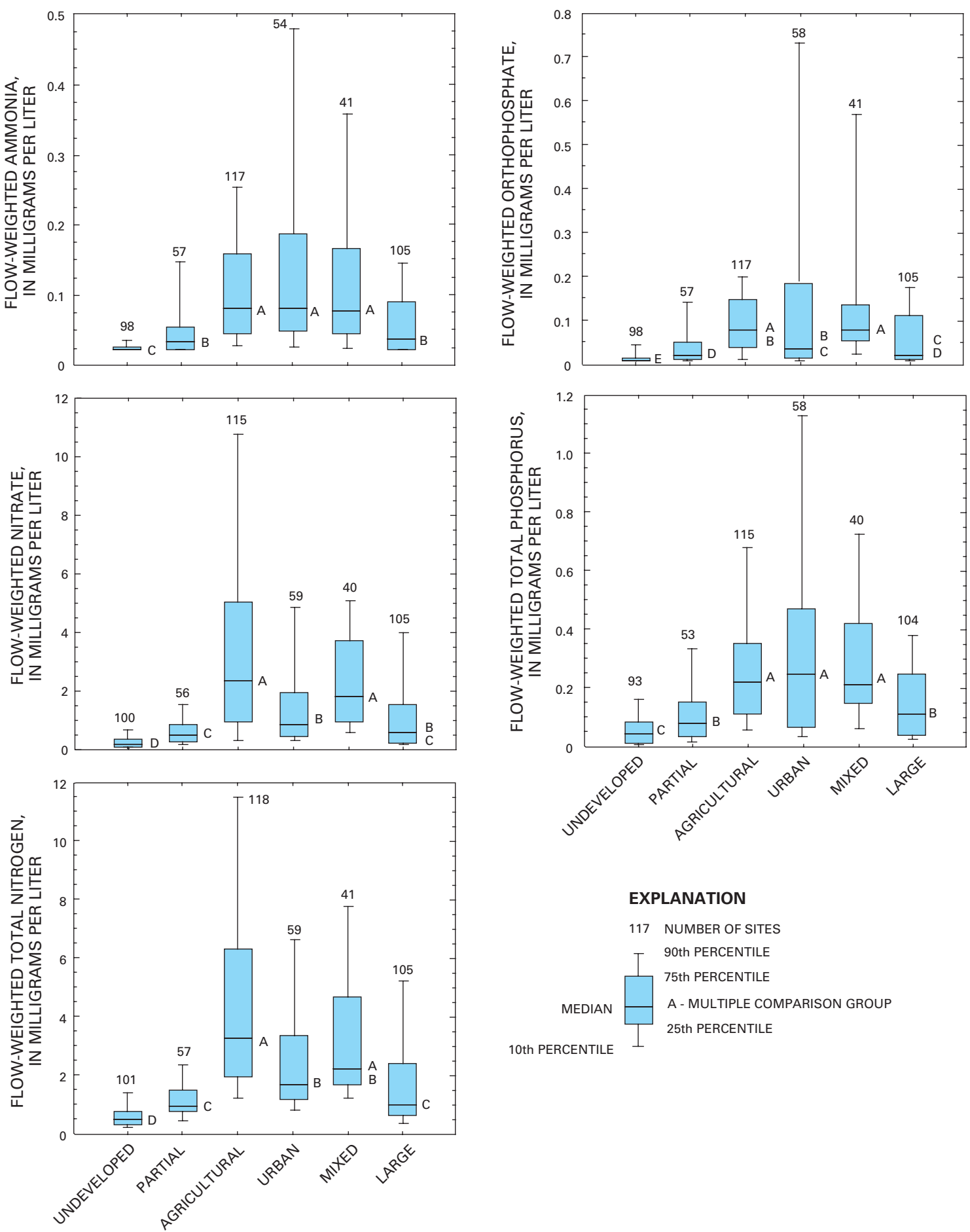

Figure 14. Box plots showing the distribution of flow-weighted nutrient concentrations by land-use category. 
are not significantly different at urban and large sites. Large watersheds generally contain many land uses, including undeveloped areas; thus, they are more similar to partially developed watersheds. Indeed, concentrations of all nutrients were not significantly different at sites classified as large or partial.

In a previous analysis of nutrient data from NAWQA study units, Mueller and others (1995) reported that concentrations of ammonia and total phosphorus were significantly higher at urban than at agricultural sites. That analysis used data from sites sampled before initiation of the NAWQA Program, and many of the urban sites were located downstream from wastewater-treatment plants (WWTPs). Large WWTPs can be major point sources of ammonia and orthophosphate. The NAWQA design was to avoid large upstream WWTPs, so most urban sites in the current data set are affected primarily by nonpoint sources of nutrients.

At some NAWQA urban sites, upstream point sources could not be avoided, and high ammonia, orthophosphate, and total phosphorus concentrations likely are due to WWTP effluent. For sites with known WWTPs, 34 percent are in the upper quartile (greater than the 75th percentile) for ammonia, 41 percent are in the upper quartile for orthophosphate, and 38 percent are in the upper quartile for total phosphorus. Fewer sites with no known WWTPs are in the upper quartiles: 21 percent for ammonia, 17 percent for orthophosphate, and 16 percent for total phosphorus. For all three of these constituents, sites downstream from WWTPs are more prevalent in the highest range of concentrations.

Differences in the distributions of nutrient yield are similar to those described for concentration. Median yields for all constituents from undeveloped watersheds are significantly less than those from other types of watersheds, and yields increase as development increases (fig. 15). Median yields from partially developed and large watersheds are not significantly different but typically are intermediate between those from undeveloped watersheds and from more developed (agricultural, urban, and mixed land-use) watersheds. Generally, median yields from agricultural, urban, and mixed land-use watersheds are not significantly different; however, nitrate yield is greater from agricultural and mixed land-use watersheds than from urban watersheds, and orthophosphate yield is greater from mixed land-use watersheds than from urban watersheds.

\section{Comparison to Background Conditions}

In the NAWQA Program, sites downstream from relatively undeveloped areas were selected to provide a baseline for comparison to sites with potential effects of urban development and agriculture. Concentrations and yields at the undeveloped sites are less than at sites in other land-use categories but cannot necessarily be considered background levels. Clark and others (2000) reported general national background concentrations and yields of nutrients, based on data from sites in some of the most pristine watersheds in the
Nation. Background concentrations were determined on the basis of flow-weighted means from each site. The distributions of flow-weighted mean nutrient concentrations for NAWQA undeveloped sites in comparison to these national background concentrations are shown in figure $16 \mathrm{~A}$.

Median concentrations for ammonia and orthophosphate at the undeveloped sites are less than the detection limits. Median concentrations of nitrate, total nitrogen, and total phosphorus are greater than the background values reported by Clark and others (2000). The reported background concentrations represent conditions of essentially no development, whereas the NAWQA sites represent conditions of relatively little development. Concentrations at many NAWQA undeveloped sites exceed background values. In general, though, concentrations at NAWQA undeveloped sites are low in relation to other NAWQA sites and provide an adequate comparison to more developed agricultural and urban conditions.

Nutrient conditions associated with different natural vegetation were investigated by dividing the NAWQA undeveloped sites according to predominant land cover: forest or rangeland $(16 B)$. Distributions for nitrogen constituents are similar, but orthophosphate and total phosphorus are greater at sites in rangeland areas. Phosphorus can have substantial geologic sources and is readily transported with sediment. The relation between total phosphorus and suspended-sediment concentrations at undeveloped sites is plotted in figure 17. Rangeland sites generally have higher sediment concentrations, probably because they occur in areas where erosion potential is greater, due to slope, soil type, and climate. This phenomenon has been specifically noted in the Yellowstone Basin study unit (Peterson and others, 2004). Phosphorus attached to sediment particles results in higher phosphorus concentrations in areas with higher suspended-sediment concentrations. In forested watersheds, erosion potential typically is less than in rangeland areas; therefore, sediment and total phosphorus concentrations are generally lower at forest sites than at rangeland sites.

Distributions of annual nutrient yields from the NAWQA undeveloped watersheds are shown in figure 18. Compared to concentrations, median yields are more similar to background values reported by Clark and others (2000). Background yields were estimated as the median of mean annual yields from more than 60 watersheds in areas where anthropogenic effects are minimal. Yield is determined by annual streamflow as well as mean concentration, so sites that have a high concentration might not have a high yield if streamflow is low. This is the case for most undeveloped sites that had the highest concentrations of total nitrogen and total phosphorus. Of the 16 sites plotted higher than the 90th percentile for total nitrogen or total phosphorus in figure 16A, 14 are located in arid to semiarid regions where mean annual runoff is less than 20 centimeters. The distributions of yield at these 14 sites were low relative to concentration; only 4 of these sites were plotted higher than the 90th percentile in figure 18, and 4 were lower than the 10th percentile. This result reinforces the conclusion that NAWQA undeveloped sites provide an adequate comparison 

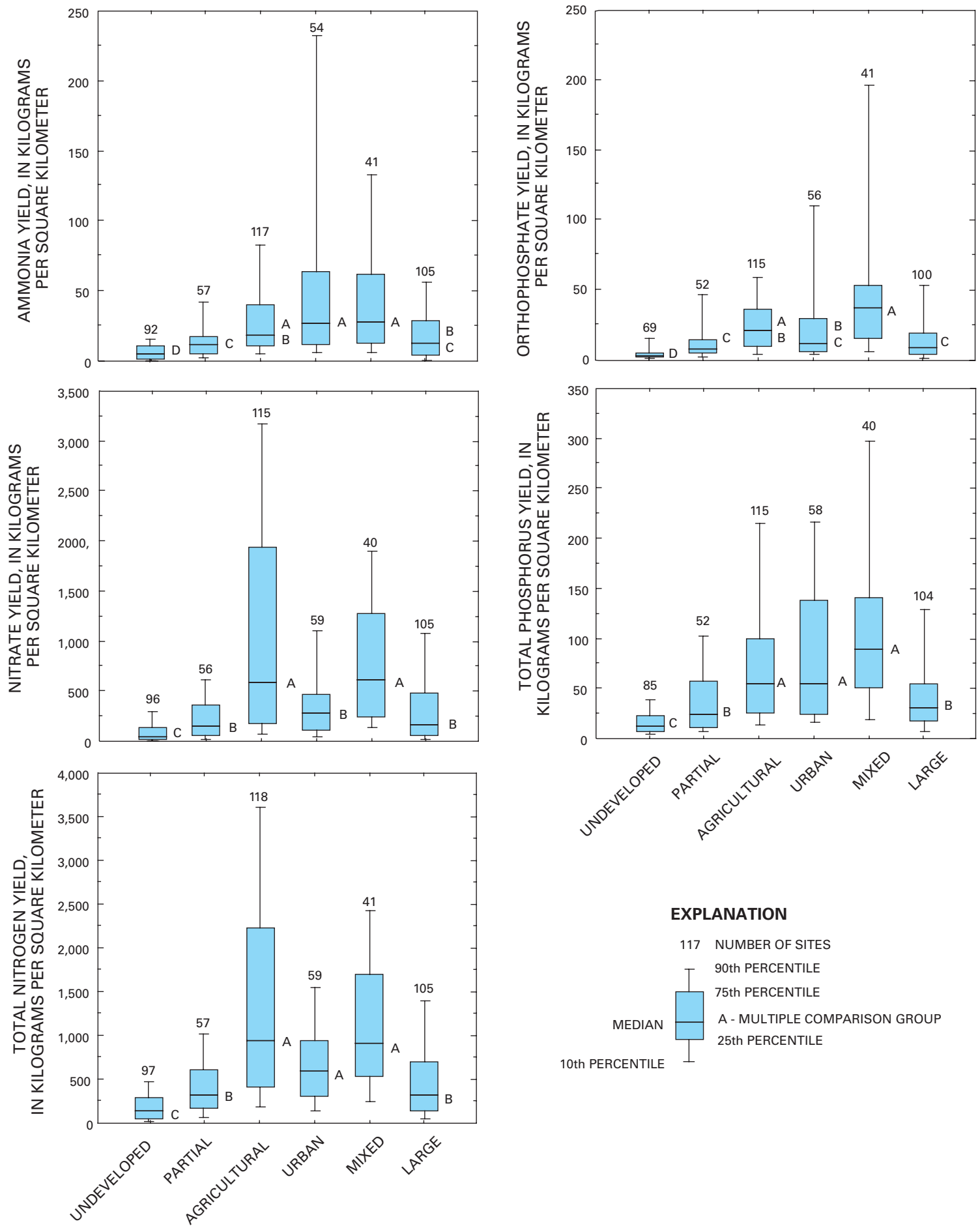

Figure 15. Box plots showing the distribution of nutrient yields by land-use category. 

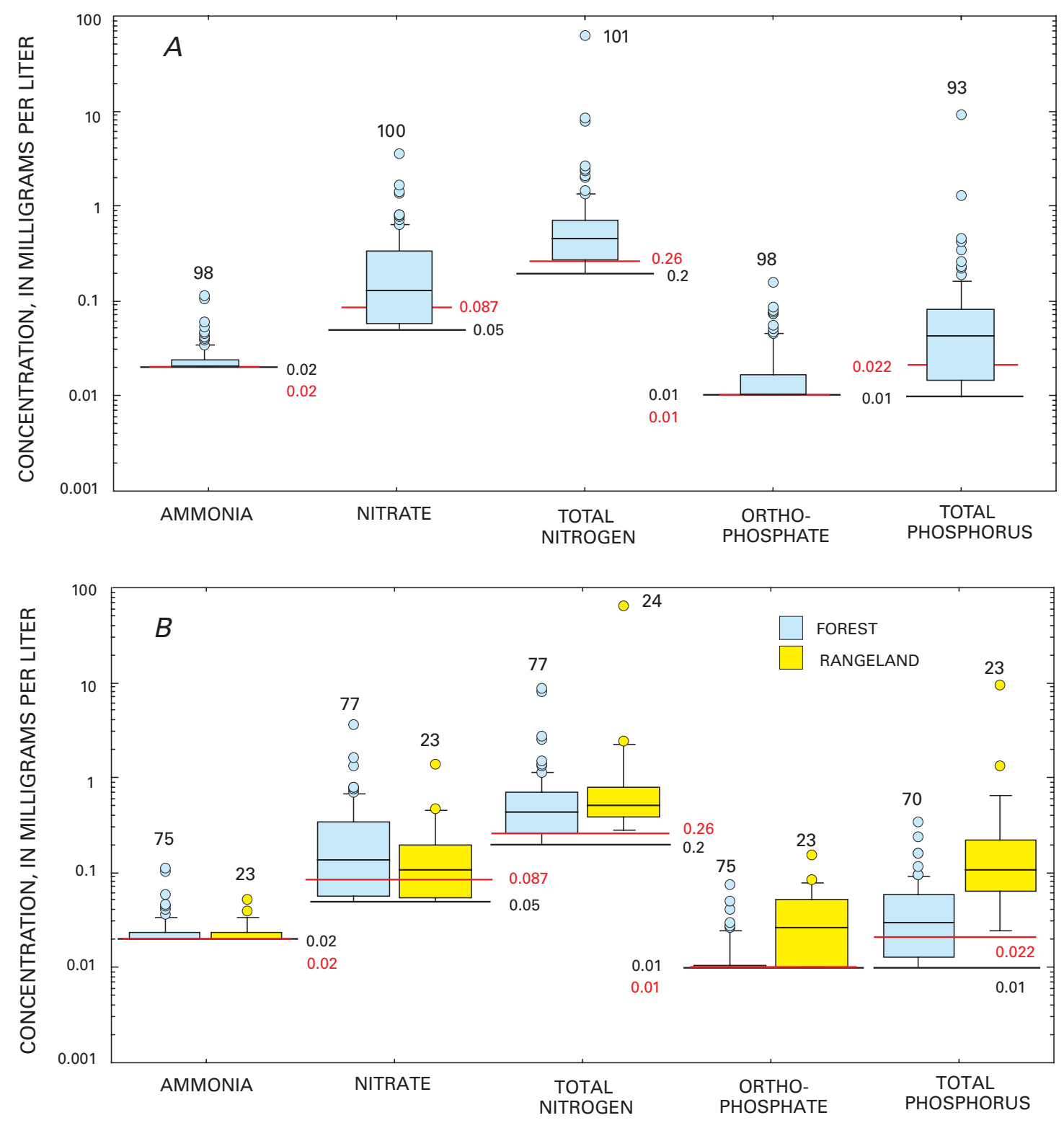

EXPLANATION

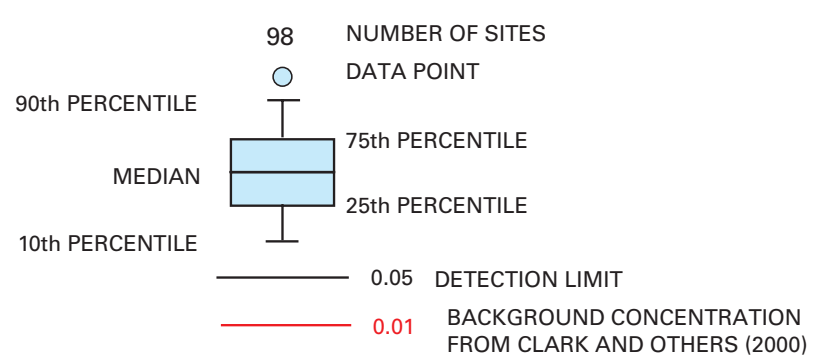

Figure 16. Box plots showing the distributions of flow-weighted mean nutrient concentrations in streams and rivers downstream from undeveloped watersheds and grouped by predominant type (forest or rangeland) of undeveloped land use. 


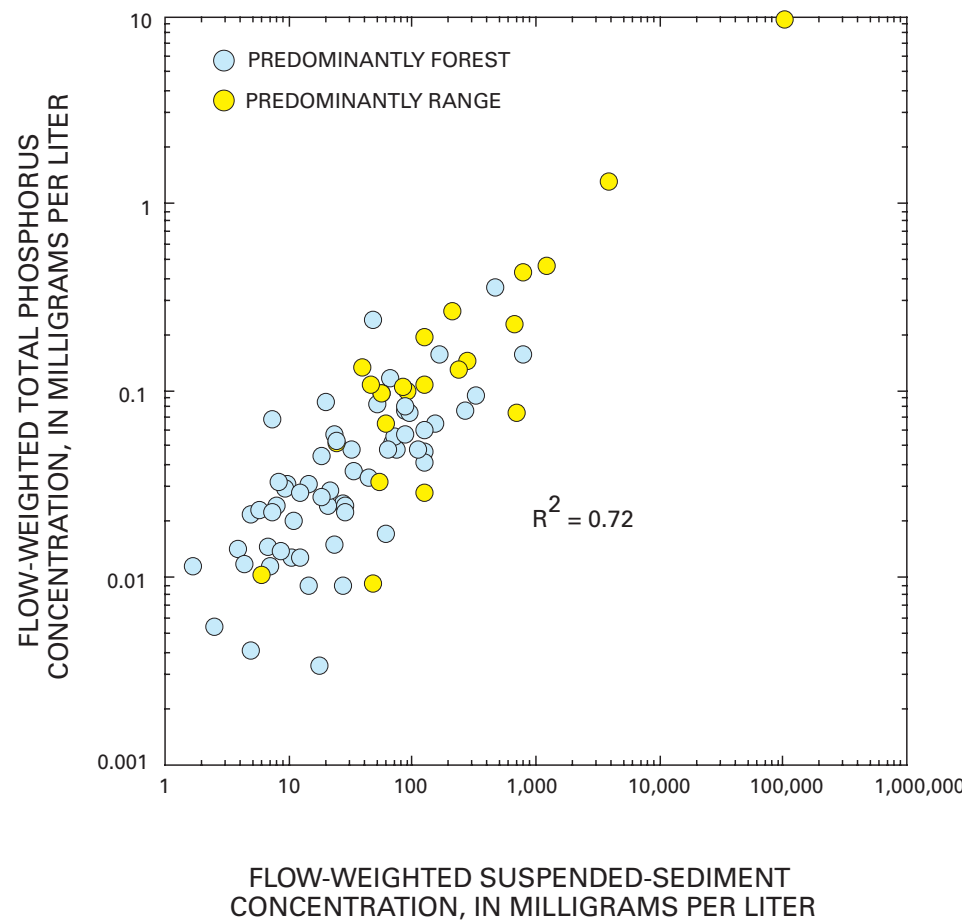

Figure 17. Relation of total phosphorus to suspended-sediment concentration at undeveloped sites.
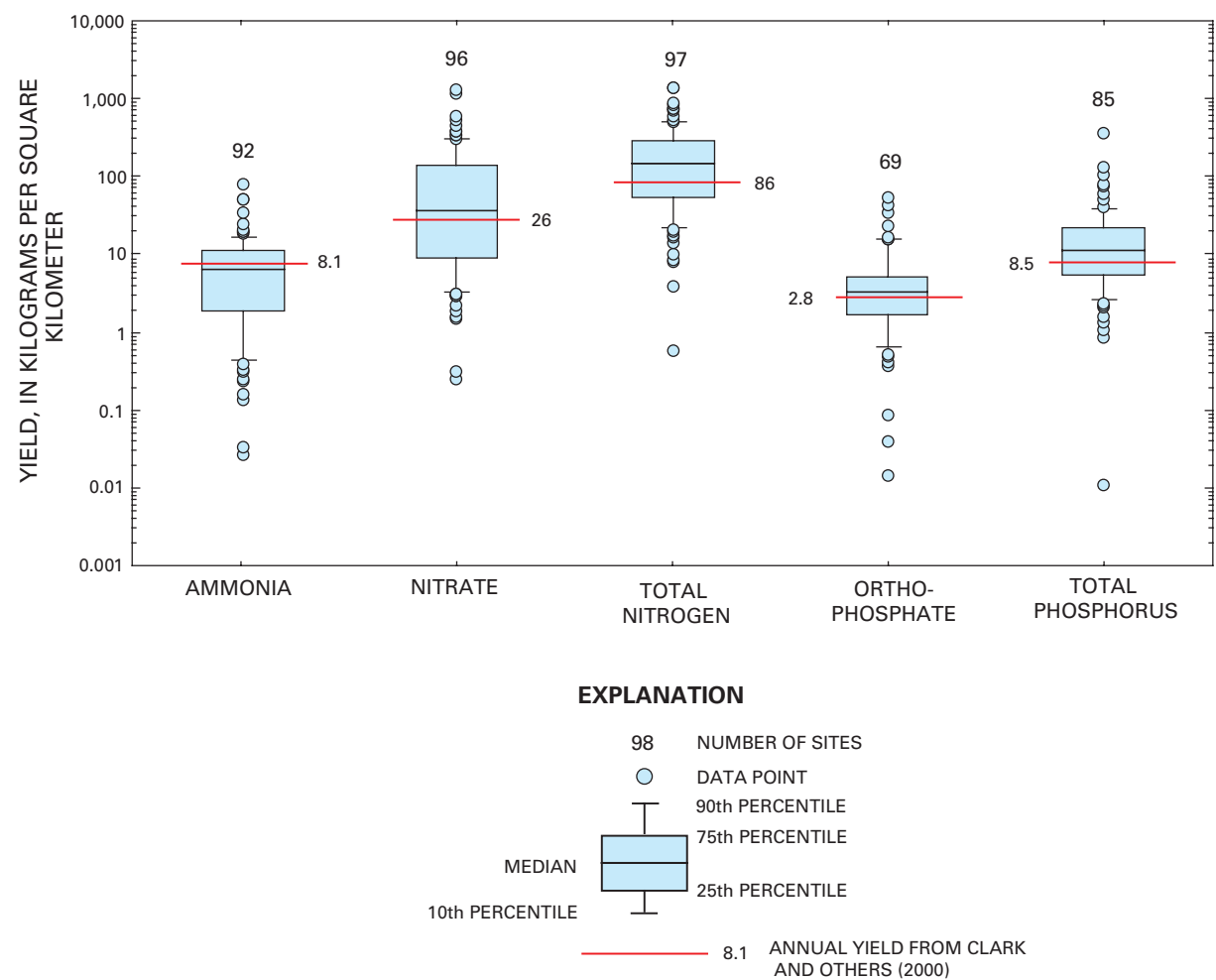

Figure 18. Box plots showing the distributions of nutrient yields from undeveloped watersheds. 
to agricultural and urban sites, even in regions where nutrient concentrations at undeveloped sites might be elevated.

In 1998, the USEPA presented a strategy for determination of national nutrient criteria (U.S. Environmental Protection Agency, 1998). Regions expected to have similar naturally occurring nutrient conditions were defined as aggregations of USEPA level-III ecoregions (fig. 19). Nitrogen and phosphorus criteria recommended within these nutrient ecoregions are meant to assist States in setting region-specific water-quality standards. The recommended criteria are intended to "identify baseline conditions of surface waters that are minimally impacted by human activities" (U.S. Environmental Protection Agency, 2000). These criteria are proposed to be a starting point for determining concentration limits needed to protect aquatic life and water use on a site-specific or subregional basis. In figure 20, flow-weighted annual mean concentrations of total nitrogen and total phosphorus at NAWQA undeveloped sites are compared to the USEPA criteria for aggregate nutrient ecoregion (U.S. Environmental Protection Agency, 2002b). Although the number of NAWQA sites per ecoregion is small, there appear to be differences in the distributions of concentrations among ecoregions for total nitrogen and total phosphorus. Thus, data from these sites provides evidence of the need for regional nutrient criteria. However, the majority of the concentrations are greater than the USEPA criteria for both nutrient constituents in almost every ecoregion. The primary exception is total nitrogen in ecoregion 9 , where concentrations at all sites are less than the criterion. In ecoregions 2 and 3, the flow-weighted mean annual concentrations of total nitrogen and phosphorus at practically every site exceed USEPA criteria. For total phosphorus, even the national background concentration $(0.022 \mathrm{mg} / \mathrm{L}$, from Clark and others, 2000) exceeds the USEPA criteria for some nutrient ecoregions. Overall, the USEPA criteria for total nitrogen were exceeded by the observed flow-weighted annual mean concentration at 72 percent of NAWQA undeveloped sites, and the criteria for total phosphorus were exceeded at 89 percent of these sites. Both criteria are exceeded more extensively at sites with more anthropogenic development in the upstream watershed. For sites classified as Agricultural, Urban, or Mixed land use (see "Ancillary Data" section of this report), exceedance of the nitrogen criteria was 96 percent and exceedance of the phosphorus criteria was 97 percent. Concentrations of both constituents were less than criteria at only one of these sites. Thus, it would appear difficult to meet the USEPA criteria at sites that have even a modest degree of upstream development.

\section{Relation of Nutrient Concentration, Yield, and Load to Sources in the Watershed}

Correlation analysis was used to investigate the relation between nutrient constituents and a variety of characteristics that represent nutrient sources in the upstream watershed. Nonpoint-source nutrient inputs include farm and urban fertilizer application, manure accumulation from livestock, and atmospheric deposition, as described previously in the "Ancillary Data" section of this report. Point-source and septic inputs were not available in a consistent, national data set, so population data were used as a surrogate. The population data were derived from a 100-meter-resolution grid of census block groups and population counts (Price, 2003) based on the 1990 Census of Population and Housing (U.S. Bureau of the Census, 1991). Geologic sources of phosphorus also could not be adequately estimated on a national scale. The primary transport mechanism of phosphorus from this source to streams and rivers is erosion, so the potential for erosion within each watershed was used as a surrogate for a possible source of particulate phosphorus. Potential erosion was determined by using the Revised Universal Soil Loss Equation (U.S. Department of Agriculture, 1997).

Correlations were tested using Spearman coefficients, which evaluate monotonic though not necessarily linear relations between two variables. Results are listed in table 3 . For comparison, this table also includes coefficients for correlations between nutrients and land use. The strongest correlations were between nutrient loads and nonpointsource input mass. The correlation coefficients (rho) for all constituents equal or exceed 0.83 , indicating that at least 69 percent $\left(100 \times 0.83^{2}\right)$ of the variation in nutrient loads can be explained by variation in input. The correlations are high probably in part because of the large range in watershed area. Very large watersheds normally have much larger inputs and outflow loads than very small watersheds. Still, these coefficients indicate a good relation between nonpoint-source nutrient inputs and nutrient outflow loads in a wide variety of streams and rivers. The best correlations with nutrient concentrations and yields were for nutrient input rates (rho $=0.43$ to 0.70 ) or percent undeveloped land (rho $=-0.49$ to -0.73). Coefficients for the relation between input rate and outflow yield were not quite as high as those between input mass and outflow load. Variations in input rates explain only about 22-45 percent of the variations in yield. However, input rates and yields are normalized to watershed area, so the range in size that might be contributing to the high correlations between input mass and outflow load has no effect on the correlations between input and yield.

Correlations between concentration or yield and nonpoint-source input rates were better for nitrate and total nitrogen (rho $=0.66$ to 0.70 ) than for ammonia, orthophosphate, and total phosphorus (rho $=0.43$ to 0.58 ). Urban sources, such as wastewater discharge, septic systems, and stormwater runoff, which can be important sources of ammonia and orthophosphate, are not included in the estimated nonpoint inputs. Correlation between yield and population density, a surrogate for urban sources, was highest for ammonia $($ rho $=0.49)$ and was approximately equivalent for all other nutrients (rho $=$ 0.38 to 0.45 ). Correlations between loads and total population had a similar pattern. Thus, these population variables represent urban sources equally well for all nutrients though, 


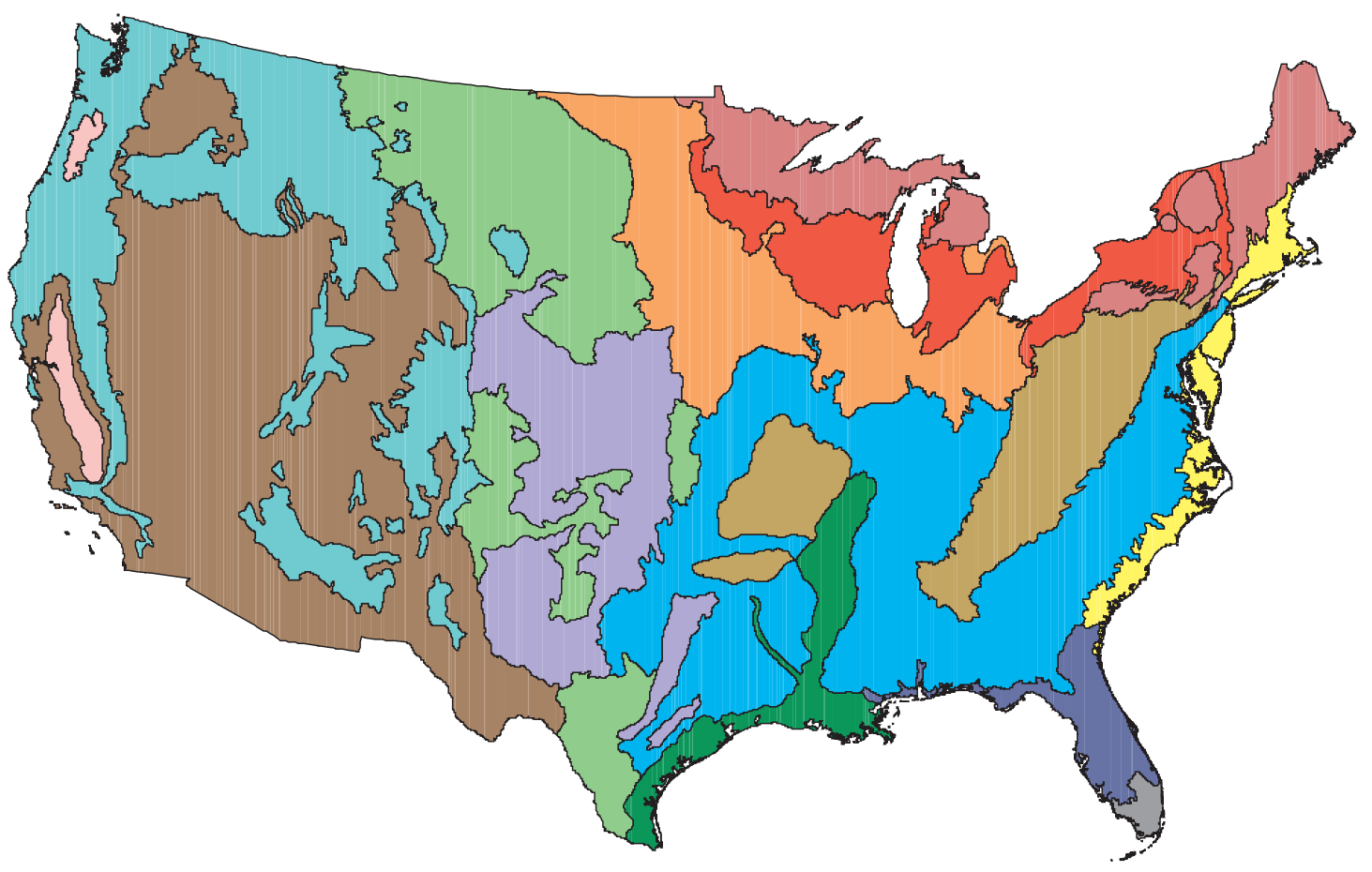

\section{EXPLANATION}

U.S. Environmental Protection Agency nutrient ecoregions

\begin{tabular}{|c|}
\hline 1-Willamette and Central Valleys \\
\hline 2-Western Forested Mountains \\
\hline 3-Xeric West \\
\hline 4-Great Plains Grass and Shrubland \\
\hline 5-South Central Cultivated Great Plains \\
\hline 6-Corn Belt and Northern Great Plains \\
\hline 7-Mostly Glaciated Dairy Region \\
\hline 8-Nutrient-Poor, Largely Glaciated Upper Midwest and Northeast \\
\hline 9-Southeastern Temperate Forested Plains and Hills \\
\hline 10-Texas-Louisiana Coastal and Mississippi Alluvial Plains \\
\hline 11-Central and Eastern Forested Uplands \\
\hline 12-Southern Coastal Plain \\
\hline 13-Southern Florida Coastal Plain \\
\hline 14-Eastern Coastal Plain \\
\hline
\end{tabular}

Figure 19. Nutrient ecoregions of the continental United States, as defined by the U.S. Environmental Protection Agency (1998). 

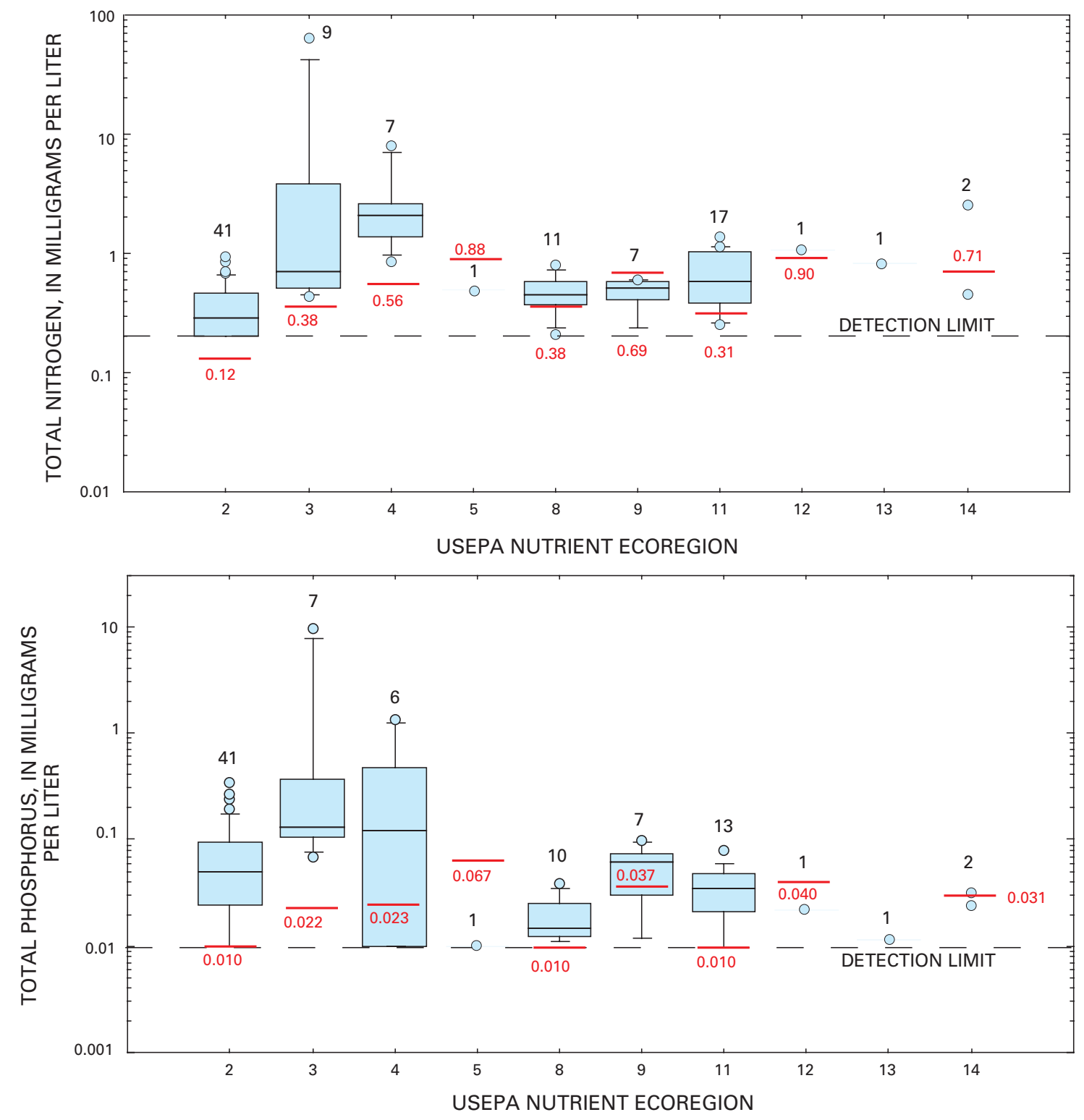

\section{EXPLANATION}

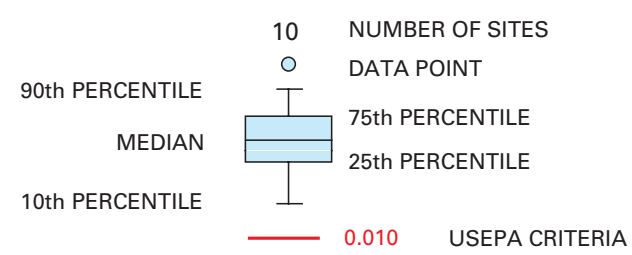

Figure 20. Box plots showing the distributions of total nitrogen and total phosphorus flow-weighted concentrations downstream from undeveloped watersheds by U.S. Environmental Protection Agency nutrient ecoregions. [USEPA criteria have not been defined for Ecoregion 13.] 
Table 3. Spearman correlation coefficients for modeled mean annual nutrient concentrations, yields, and loads with selected characteristics of the upstream watersheds.

[Conc, flow-weighted mean concentration; $\mathrm{kg} / \mathrm{km}^{2}$, kilograms per square kilometer; $\mathrm{kg}$, kilograms; --, not significant (p-value greater than 0.01); values in bold type exceed 0.5 ]

\begin{tabular}{|c|c|c|c|c|c|c|c|c|c|}
\hline \multirow{2}{*}{$\begin{array}{l}\text { Characteristic of the upstream } \\
\text { watershed }\end{array}$} & \multicolumn{3}{|c|}{ Ammonia } & \multicolumn{3}{|c|}{ Nitrate } & \multicolumn{3}{|c|}{ Total nitrogen } \\
\hline & Conc & Yield & Load & Conc & Yield & Load & Conc & Yield & Load \\
\hline \multicolumn{10}{|l|}{ Nonpoint-source input } \\
\hline Nitrogen input rate, $\mathrm{kg} / \mathrm{km}^{2}$ & 0.53 & 0.47 & 0.16 & 0.68 & 0.66 & 0.37 & 0.70 & 0.67 & 0.28 \\
\hline Nitrogen input mass, $\mathrm{kg}$ & 0.17 & -- & 0.83 & 0.22 & -- & 0.83 & 0.22 & -- & 0.89 \\
\hline \multicolumn{10}{|l|}{ Surrogates for other input } \\
\hline Population density, per $\mathrm{km}^{2}$ & 0.40 & 0.49 & -- & 0.36 & 0.45 & 0.16 & 0.30 & 0.44 & -- \\
\hline Total population & 0.22 & -- & 0.73 & 0.15 & -- & 0.66 & -- & -- & 0.70 \\
\hline Erosion potential & -- & 0.26 & -- & 0.22 & 0.41 & 0.25 & -- & 0.37 & 0.17 \\
\hline \multicolumn{10}{|l|}{ Land use } \\
\hline Percent urban land & 0.39 & 0.44 & 0.16 & 0.33 & 0.39 & 0.17 & 0.28 & 0.39 & -- \\
\hline Percent agricultural land & 0.46 & 0.36 & 0.20 & 0.62 & 0.57 & 0.42 & 0.64 & 0.58 & 0.34 \\
\hline Percent undeveloped land & -0.63 & -0.55 & -- & -0.68 & -0.66 & -0.23 & -0.73 & -0.70 & -0.14 \\
\hline \multirow{2}{*}{$\begin{array}{c}\text { Characteristic of the upstream } \\
\text { watershed }\end{array}$} & \multicolumn{4}{|c|}{ Orthophosphate } & \multicolumn{3}{|c|}{ Total phosphorus } & & \\
\hline & & & Yield & Load & Conc & Yield & Load & & \\
\hline \multicolumn{10}{|l|}{ Nonpoint-source input } \\
\hline Phosphorus input rate, $\mathrm{kg} / \mathrm{km}^{2}$ & & .53 & 0.58 & 0.22 & 0.43 & 0.49 & 0.15 & & \\
\hline Phosphorus input mass, $\mathrm{kg}$ & & 29 & -- & 0.85 & 0.28 & -- & 0.83 & & \\
\hline \multicolumn{10}{|l|}{ Surrogates for other input } \\
\hline Population density, per $\mathrm{km}^{2}$ & & 20 & 0.38 & -- & 0.19 & 0.42 & -- & & \\
\hline Total population & & 17 & -- & 0.71 & 0.18 & -- & 0.71 & & \\
\hline Erosion potential & & -- & 0.37 & 0.15 & -- & 0.36 & 0.14 & & \\
\hline \multicolumn{10}{|l|}{ Land use } \\
\hline Percent urban land & & .21 & 0.36 & -- & 0.21 & 0.40 & -- & & \\
\hline Percent agricultural land & & 49 & 0.52 & 0.25 & 0.40 & 0.42 & 0.19 & & \\
\hline Percent undeveloped land & & .53 & -0.60 & -- & -0.49 & -0.58 & -- & & \\
\hline
\end{tabular}

except for ammonia, their correlations with nutrient yield are weaker than the correlations between yield and nonpointsource inputs.

In general, the correlations between total phosphorus and the nonpoint-source or urban input variables are as weak as or weaker than those for any other nutrients. In many streams, particularly in arid and semiarid areas, suspended sediment is a major transport mechanism for phosphorus, and the source of phosphorus in sediment can be geologic rather than fertilizer or manure. Erosion potential was included as a surrogate for this source; however, the correlations between total phosphorus and erosion potential were not strong and were no better than the correlations for other nutrients. Thus, the erosion-potential variable, as determined for this study, does not provide an adequate surrogate for sources of particulate phosphorus in streams and rivers.

Correlations between concentration or yield and nutrient input rates are of similar magnitude but opposite sign to correlations between concentration or yield and undeveloped land. Numerically, undeveloped land is functioning as a surrogate for lack of nutrient inputs. In fact, these two watershed characteristics are highly correlated; the Spearman correlations between undeveloped land use and nutrient input rate are -0.86 for nitrogen and -0.80 for phosphorus.

The relation between annual nutrient inputs and simulated annual outflow loads of total nitrogen and total phosphorus are plotted for individual sampling sites in figure 21 . Different symbols are used for major land uses (undeveloped, agricultural, and urban) and for large watersheds. Partially developed and mixed land-use sites are not shown. The dashed lines indicate nutrient retention in the watershed, assuming the estimated nonpoint-source inputs and the simulated outflow loads account for all nitrogen and phosphorus movement into and out of the watershed. The stronger correlation between inputs and outflow loads for nitrogen is obvious, but there is a great deal of scatter in both plots. For many sites, primarily in undeveloped and urban areas, apparent retention is less than 50 percent; in some cases, outflow load exceeds input. 

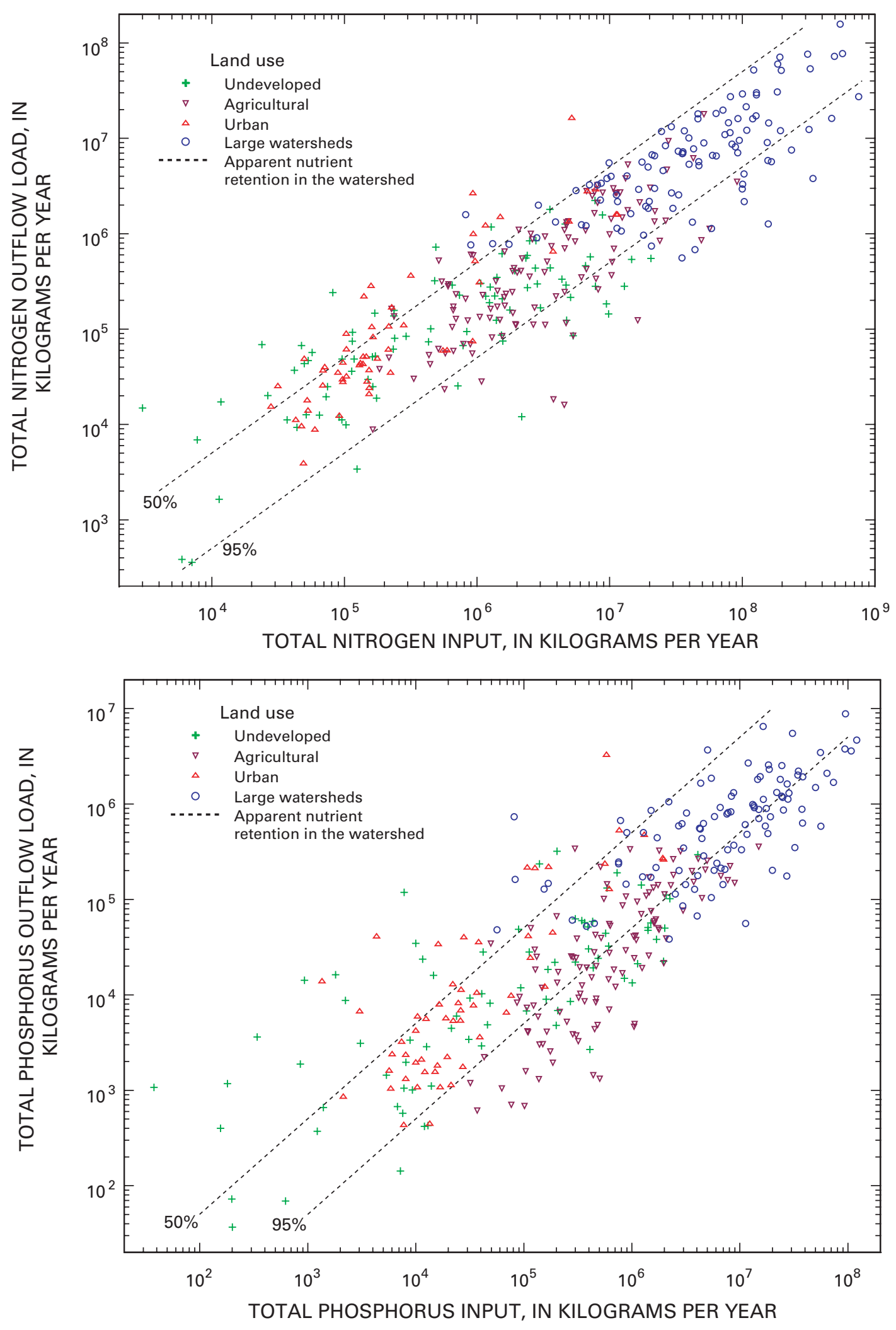

Figure 21. Relation of nutrient inputs and outflow loads for selected National Water-Quality Assessment sites, with dashed lines showing apparent nutrient retention in the watershed. 
Because this situation is not possible over the long term, there must be a problem with either the simulated load or the estimated input. For the urban sites, the most likely explanation is that point sources or septic systems are contributing a substantial amount of nutrients that are not included in the input estimates. If all sources were accounted for, the urban sites probably would show less scatter and more realistic retention. For undeveloped watersheds with low retention, an explanation is not so obvious. Many of these sites are in study units in the Northwest (WILL, PUGT, NROK, and USNK; fig. 1). Atmospheric deposition, the primary source of nitrogen in many undeveloped watersheds, could be underestimated throughout this region. Another possibility is that some regionally unique source of nutrients, such as salmon carcasses in coastal streams, is not represented. Whatever the cause, estimates of nonpoint-source nutrient input could be biased low throughout this region.

For other sites plotted in figure 21, the apparent nutrient retention in the watershed is greater than 95 percent. A large number of these sites are in agricultural areas, where export of nutrients in harvested crops likely is a substantial output that is unaccounted for by the outflow load. Thus, the true retention in the watershed is not as high as indicated on the plots. The remaining sites with high retention are primarily in undeveloped areas or large watersheds. The common characteristic of many of these sites is that they are located in semiarid rangeland areas of the Northern Plains, Southwest, or the inland Northwest, where manure can be a major source of nutrient input. In these watersheds, transport of nutrients to streams can be severely limited, occurring primarily during the most intense rainfall. Nutrients might accumulate for years and be incorporated into plant material or, in the case of phosphorus, attached to soil particles. Most of the agricultural sites with the highest apparent retention also are in semiarid settings.

General differences in the relation of nutrient inputs and outflow loads among land-use settings can be more easily shown by plotting smoothed curves instead of individual sites. The lines shown in figure 22 are locally weighted scatterplot smooth (LOWESS) curves through the center of mass of the data points for each land-use type. The difference between agricultural and urban sites is most obvious. The slope of the relation between input and outflow load is about the same, but agricultural sites have a higher apparent retention than urban sites. This pattern reiterates the underestimation of output (harvest) at agricultural sites and the underestimation of input (septic sources) at urban sites. The curves for sites in undeveloped areas and downstream from large watersheds show a general pattern of low retention associated with low input and high retention associated with high input. This pattern is more exaggerated for phosphorus than for nitrogen. One influence on this pattern could be regional differences, with high retention in more arid areas in the West and low retention, perhaps in addition to underestimation of input, in the Northwest. The upper range of nutrient inputs for sites in undeveloped areas overlaps the lower range for sites downstream from large watersheds. Within this overlapping range of inputs, outflow loads from large watersheds are much higher than loads from undeveloped areas. The primary difference between sites in these two categories is runoff. At the 20 large-watershed sites with the lowest nutrient inputs, median runoff during NAWQA sampling was about 58 centimeters per year, but at the 20 undeveloped sites with the highest inputs, median runoff during NAWQA sampling was less than 8 centimeters per year. In watersheds that have higher runoff, the potential for transport of nutrients to streams is greater. Thus, the difference in loads between these two groups of sites, which have similar inputs, could be attributable to the differences in runoff.

\section{Summary and Conclusions}

Nutrient compounds of nitrogen and phosphorus were investigated in streams and rivers sampled as part of the U.S. Geological Survey National Water-Quality Assessment (NAWQA) Program. Nutrient data were collected in 20 NAWQA study units during 1992-95, 16 study units during 1996-98, and 15 study units during 1999-2001. To facilitate comparisons among sampling sites with variable sampling frequency, daily loads were determined by using regression models that relate constituent transport to streamflow and time. Model results were used to compute mean annual loads, yields, and concentrations of ammonia, nitrate, total nitrogen, orthophosphate, and total phosphorus, which were compared among stream and river sampling sites.

The distribution of nutrients in streams and rivers across the Nation can be described spatially and temporally. Geographic patterns in nutrient concentrations and yields and the relation of land use to concentrations and yields provide the framework to assess areas of potential concern. Seasonal variation in nitrogen and phosphorus concentrations can be used to describe national and regional patterns. Variations in the distribution of nutrients in streams and rivers on a broad national scale reflect differences in the sources of nutrient inputs to the upstream watersheds plus watershed characteristics that affect movement of those nutrients. Nutrient inputs are affected by land use and include nonpoint sources of fertilizer, manure, and atmospheric deposition plus point and nonpoint sources of septic effluent. Movement of nutrients includes mobilization of nonpoint-source inputs on the landscape and transport to streams and rivers.

Nutrient concentrations and yields generally increase with anthropogenic development in the watershed. Median concentrations and yields for all constituents at sites downstream from undeveloped areas are less than at sites downstream from agricultural or urban areas. Concentrations of total nitrogen are slightly elevated at some undeveloped sites in areas of greater atmospheric nitrogen deposition. Total phosphorus concentrations are high at some undeveloped sites in the Southwest and Northern Plains where erosion is a predominant transport process, contributing sediment and attached phosphorus compounds to the streams. Geographic 

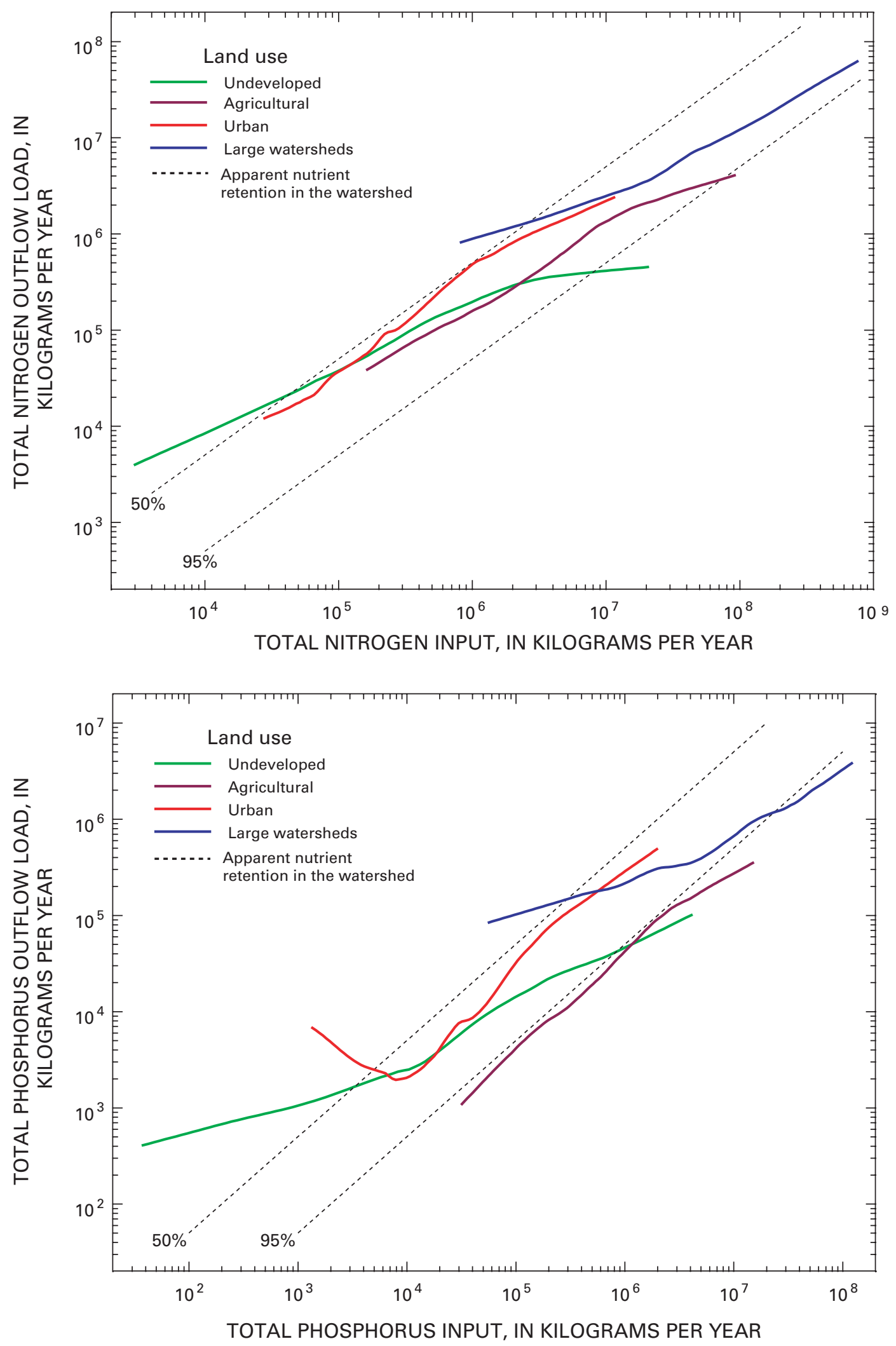

Figure 22. LOWESS smooth curves of the general relation between nutrient inputs and outflow loads for watersheds in selected land-use categories. 
variation in concentrations of nitrogen and phosphorus at undeveloped sites is evidence of the need for regional nutrient criteria.

Concentrations of ammonia, orthophosphate, and total phosphorus at agricultural and urban sites are not significantly different; however, concentrations of nitrate and total nitrogen are higher at agricultural sites than at urban sites. Total nitrogen concentrations at agricultural sites are higher in areas of high nitrogen input or enhanced transport, such as irrigation or artificial drainage that can move water rapidly from cropland to streams. These areas include the Midwest, the Northern Plains, and much of the Western United States. Concentrations are lower in the Southeast, where more denitrification can occur during transport of nitrogen compounds in shallow ground water. Total phosphorus concentrations also are high in urban areas but are not elevated to the same extent as total nitrogen concentrations in agricultural areas. Some regional differences are apparent. High concentrations of total phosphorus are relatively more common than high concentrations of total nitrogen at urban sites through parts of the Southeast, Southwest, and Hawaii. High concentrations of ammonia and orthophosphate, which are common in septic effluent, are more prevalent at sites downstream from wastewater-treatment plants.

Total nitrogen concentrations at sites downstream from large watersheds (in terms of area and streamflow) are higher in Midwest agricultural areas and lower in the Western United States, where agricultural and urban development is less extensive. Total phosphorus concentrations at large sites are higher in areas of greater potential erosion and low overall runoff.

Yields of total nitrogen and total phosphorus generally correspond to patterns of input and streamflow. Yields at undeveloped and large sites are typically low in the semiarid to arid interior West, compared to more humid areas in the Eastern United States and along the West Coast. However, yields are moderate to high at agricultural sites in the interior West, where streamflow is augmented by return flows from irrigated areas.

Seasonal patterns in concentrations of total nitrogen generally mirror seasonal patterns in streamflow in the Eastern United States but are inverse to seasonal patterns in streamflow in the interior West. Total phosphorus concentrations typically have the opposite regional relation. These regional differences could be affected by differences in the mechanism for mobilization and transport, which seems to favor movement of nitrogen during high-flow seasons in the Eastern United States and during low-flow seasons the interior West. For phosphorus, transport is more associated with erosion, which is more likely to occur during high-flow seasons and is more common in the interior West than in the Eastern United States.

To assist states in adopting water-quality standards, the USEPA has developed regional nutrient criteria. These criteria were compared to mean annual flow-weighted concentra- tions of total nitrogen and total phosphorus for NAWQA sites classified as agricultural, urban, or mixed land use. Criteria for both constituents were exceeded at 96 to 97 percent of these sites. At NAWQA undeveloped sites, exceedance of the regional criteria was 72 percent for total nitrogen and 89 percent for total phosphorus. Thus, it would appear difficult to meet the USEPA criteria at sites that have even a modest degree of development upstream.

In addition to land use, other characteristics of the upstream watershed can influence nutrient concentrations, yields, and loads at stream and river sampling sites. The strongest correlations were between nutrient loads and nonpointsource input mass. For all constituents the variation in input mass explained at least 69 percent of the variation in outflow loads. Correlations between nonpoint-source input rates and outflow yields were not quite as good; variation in input rates explained only about $22-45$ percent of the variations in nutrient yields. Correlations between input rates and outflow concentration or yield were better for nitrate and total nitrogen than for ammonia, orthophosphate, and total phosphorus, all three of which can be affected by sources that were not included in the estimated inputs. For ammonia, the correlation between yield and population density, a surrogate for septic sources, was higher than the correlation between yield and nitrogen input rate. The weakest correlations with inputsources (or surrogates) were for total phosphorus.

Differences between annual nonpoint-source inputs and simulated annual outflow loads of total nitrogen and total phosphorus indicated an apparent retention of less than 50 percent in many urban areas. In contrast, the apparent nutrient retention in many agricultural areas was greater than 95 percent. This pattern indicates an underestimation of nutrient outflow at agricultural sites and an underestimation of input at urban sites. Inclusion of nutrient output in crop harvest could improve estimates at agricultural sites, and inclusion of point-source inputs could improve estimates at urban sites.

Overall, the distributions of nutrient concentrations, yields, and loads at stream and river sampling sites have distinct regional and seasonal patterns, but good general correlation to land use and nonpoint-source inputs at a national scale. Estimation of nutrient outflow, on the basis of these correlations, likely could be improved if nationally consistent data were available for additional watershed characteristics.

\section{References Cited}

Akaike, Hirotugu, 1981, Likelihood of a model and information criterion: Journal of Econometrics, v. 16, p. 3-14.

Bradu, Dan, and Mundlak, Yair, 1970, Estimation in lognormal linear models: Journal of the American Statistical Association, v. 65, no. 329, p. 198-211. 
Carpenter, S.R., Caraco, N.F., Correll, D.L., Howarth, R.W., Sharpley, A.N., and Smith, V.H., 1998, Nonpoint pollution of surface water with phosphorus and nitrogen: Ecological Applications, v. 8, no. 3, p. 559-568.

Clark, G.M., Mueller, D.K., and Mast, M.A., 2000, Nutrients concentrations and yields in undeveloped stream basins of the United States: Journal of American Water Resources Association, v. 36, no. 4, p. 849-860.

Cohn, T.A., Caulder, D.L., Gilroy, E.J., Zynjuk, L.D., and Summers, R.M., 1992, The validity of a simple statistical model for estimating fluvial constituent loads -- An empirical study involving nutrient loads entering Chesapeake Bay: Water Resources Research, v. 28, no. 9, p. 2353-2363.

Cohn, T.A., DeLong, L.L., Gilroy, E.J., Hirsch, R.M., and Wells, D.K., 1989, Estimating constituent loads: Water Resources Research, v. 25, no. 5, p. 937-942.

Cohn, T.A., Gilroy, E.J., and Baier, W.G., 1992, Estimating fluvial transport of trace constituents using a regression model with data subject to censoring, in Proceedings of the Section on Statistics and the Environment: American Statistical Association, Boston, Mass., August 9-13, 1992, p. 142-151.

Conover, W.J., and Iman, R.L., 1981, Rank transformation as a bridge between parametric and nonparametric statistics: The American Statistician, v. 35, no. 3, p. 124-129.

Crawford, C.G., 1991, Estimation of suspended-sediment rating curves and mean suspended-sediment loads: Journal of Hydrology, v. 129, p. 331-348.

Efron, Bradley, 1982, The jackknife, the bootstrap, and other resampling plans: CBMS-NSF Regional Conference Series in Applied Mathematics, 38, Society for Industrial and Applied Mathematics, Philadelphia, 92 p.

Fenelon, J.M., 1998, Water quality in the White River Basin, Indiana, 1992-96: U.S. Geological Survey Circular 1150, $34 \mathrm{p}$.

Fishman, M.J., 1993, Methods of analysis by the U.S. Geological Survey National Water Quality Laboratory - Determination of inorganic and organic constituents in water and fluvial sediments: U.S. Geological Survey Open-File Report 93-125, $217 \mathrm{p}$.

Gilliom, R.J., Alley, W.M., and Gurtz, M.E., 1995, Design of the National Water-Quality Assessment Program-Occurrence and distribution of water-quality conditions: U.S. Geological Survey Circular 1112, 33 p.
Goolsby, D.A., and Battaglin, W.A., 1995, Effects of episodic events on the transport of nutrients to the Gulf of Mexico: Proceedings of First Gulf of Mexico Hypoxia Management Conference, December 5-6, Kenner, La., p. 8.

Groschen, G.E., Arnold, T.L., Harris, M.A., Dupre, D.H., Fitzpatrick, F.A., Scudder, B.C., Morrow, W.S. Jr., Terrio, P.J., Watner, K.L., and Murphy, E.A., 2004, Water quality in the Upper Illinois River Basin, Illinois, Indiana, and Wisconsin, 1999-2001: U.S. Geological Survey Circular $1230,32 \mathrm{p}$.

Hamilton, P.A., Miller, T.L., and Myers, D.N., 2004, Water quality in the Nation's streams and aquifers-Overview of selected findings, 1991-2001: U.S. Geological Survey Circular 1265, 20 p.

Helsel, D.R., and Cohn, T.A., 1988, Estimation of descriptive statistics for multiply censored water quality data: Water Resources Research, v. 24, no. 12, p. 1997-2004.

Helsel, D.R., and Hirsch, R.M., 1992, Statistical methods in water resources: Amsterdam, Elsevier Science B.V., 529 p.

Justic, Dubravko, Rabalais, N.N., Turner, R.E., and Wiseman, W.J., 1993, Seasonal coupling between riverborne nutrients, net productivity and hypoxia: Marine Pollution Bulletin, v. 26, no. 4, p. 184-189.

Likes, Jiri, 1980, Variance of the MVUE for lognormal variance: Technometrics, v. 22, no. 2, p. 253-258.

Mueller, D.K., Hamilton, P.A., Helsel, D.R., Hitt, K.J., and Ruddy, B.C., 1995, Nutrients in ground water and surface water of the United States--An analysis of data through 1992: U.S. Geological Survey Water-Resources Investigations Report 95-4031, 74 p.

Mueller, D.K., and Helsel, D.K., 1996, Nutrients in the Nation's waters--Too much of a good thing?: U.S. Geological Survey Circular 1136, 24 p.

Mueller, D.K., Martin, J.D., and Lopes, T.J., 1997, Qualitycontrol design for surface-water sampling in the National Water-Quality Assessment Program: U.S. Geological Survey Open-File Report 97-223, 17 p.

Mueller, D.K., and Spahr, N.E., 2005, Water-quality, streamflow, and ancillary data for nutrients in streams and rivers across the Nation, 1992-2001: U.S. Geological Survey Data Series 152. Available online at: http://pubs.usgs.gov/ ds/2005/152/ accessed December 2005. 
Nakagaki, Naomi, and Wolock, D.M., 2005, Estimation of agricultural pesticide use in drainage basins using land cover maps and county pesticide data: U.S. Geological Survey Open-File Report 2005-1188, 46 p.

Patton, C.J., and Truitt, E.P., 1992, Methods of analysis by the U.S. Geological Survey National Water Quality Laboratory-Determination of total phosphorus by a Kjeldahl digestion method and an automated colorimetric finish that includes dialysis: U.S. Geological Survey Open-File Report 92-146, 39 p.

Patton, C.J., and Truitt, E.P., 2000, Methods of analysis by the U.S. Geological Survey National Water Quality Laboratory-Determination of ammonium plus organic nitrogen by a Kjeldahl digestion method and an automated photometric finish that includes digest cleanup by gas diffusion: U.S. Geological Survey Open-File Report 2000-170, 31 p.

Peterson, D.A., Miller, K.A., Bartos, T.T., Clark, M.L., Porter, S.D., and Quinn, T.L., 2004, Water quality in the Yellowstone River Basin, Wyoming, Montana, and North Dakota, 1999-2001; U.S. Geological Survey Circular 1234, 34 p.

Price, C.V., 2003, 1990 population density by block group for the conterminous United States. Digital map available online at: http://water.usgs.gov/GIS/metadata/usgswrd/ XML/uspopd90x10g.xml accessed June 2004.

Rabalais, N.N., Turner, R.E., Justic, D., Dortch, Q., Wiseman, W.J., and Gupta, B.K.S., 1996, Nutrient changes in the Mississippi River and system responses on the adjacent continental shelf: Estuaries, v. 19, no. 2b, p. 386-407.

Ruddy, B.C., Lorenz, D.L., and Mueller, D.K., 2006, Countylevel estimates of nutrient inputs from fertilizer, manure, and atmospheric-deposition sources in the conterminous United States, 1982-2001: U.S. Geological Survey Scientific Investigations Report 2006-5012, 17 p. Available online at: http://pubs.usgs.gov/sir/2006/5012/ accessed May 2006.

Runkel, R.L., Crawford, C.G., and Cohn, T.A., 2004, Load estimator (LOADEST)--A FORTRAN program for estimating constituent loads in streams and rivers: U.S. Geological Survey Techniques and Methods, book 4, chap. A5, 69 p.

Seaber, P.R., Kapinos, F.P., and Knapp, G.L., 1987, Hydrologic unit maps: U.S. Geological Survey Water-Supply Paper 2294, 63 p.

Shacklette, H.T., Hamilton, J.C., Boerngen, J.G., and Bowles, J.M., 1971, Elemental composition of surficial materials in the conterminous United States: U.S. Geological Survey Professional Paper 574-D, 71 p.
Shelton, L.R., 1994, Field guide for collecting and processing stream-water samples for the National Water-Quality Assessment Program: U.S. Geological Survey Open-File Report 94-455, $42 \mathrm{p}$.

Sullivan, D.J., Peterson, E.M., and Richards, K.D., 1995, Environmental setting of fixed sites in the Western Lake Michigan Drainages, Michigan and Wisconsin: U.S. Geological Survey Water-Resources Investigations Report 95-4211-A, $30 \mathrm{p}$.

Turnbull, B.W., and Weiss, Lionel, 1978, A likelihood ratio statistic for testing goodness of fit with randomly censored data: Biometrics, v. 34, p. 367-375.

U.S. Bureau of the Census, 1991, Census of population and housing, 1990 - Public Law (P.L.P 94-171: U.S. Bureau of the Census, Washington D.C., digital tabular data on CD-ROM. Available online at: http://www.census.gov/main/ www/cen1990.html accessed June 2004.

U.S. Department of Agriculture, 1997, Predicting soil erosion by water-A guide to conservation planning with the Revised Universal Soil Loss Equation (RUSLE): Agriculture Handbook 703, 384 p.

U.S. Environmental Protection Agency, 1993, Methods for the determination of inorganic substances in environmental samples: Environmental Monitoring Systems Laboratory, Cincinnati, Ohio, U.S. Environmental Protection Agency, EPA/600/R-93/100, variously paginated.

U.S. Environmental Protection Agency, 1998, National strategy for the development of regional nutrient criteria: U.S. Environmental Protection Agency Office of Water Fact Sheet EPA-822-F-98-002. Available online at: http://epa. gov/waterscience/criteria/nutrient/nutsi.html accessed January 2005.

U.S. Environmental Protection Agency, 2000, Ecoregional nutrient criteria fact sheet. Available online at: $h t t p: / / w w w$. epa.gov/waterscience/criteria/nutrient/ecoregions/factsheet. html accessed January 2005.

U.S. Environmental Protection Agency, 2002a, National water quality inventory-2000 report: U.S. Environmental Protection Agency Office of Water Report EPA-841-R-02-001, 207 p. Available online at: http://www.epa.gov/305b/ 2000report/ accessed October 2003.

U.S. Environmental Protection Agency, 2002b, Summary table for the nutrient criteria documents: U.S. Environmental Protection Agency Office of Water. Available online at: http://www.epa.gov/waterscience/criteria/nutrient/ ecoregions/sumtable.pdf accessed January 2005. 
U.S. Environmental Protection Agency, 2003, National primary drinking water standards: U.S. Environmental Protection Agency Office of Water Report EPA 816-F-03-016. Available online at: http://www.epa.gov/safewater/mcl. html\#mcls accessed May 2006.

U.S. Geological Survey, variously dated, National field manual for the collection of water-quality data: U.S. Geological Survey Techniques of Water-Resources Investigations, book 9, chaps. A1-A9. Available online at: http://pubs.water. usgs.gov/twri9A accessed June 2004.

U.S. Geological Survey, 1999, The quality of our Nation's waters-Nutrients and pesticides: U.S. Geological Survey Circular 1225, $82 \mathrm{p}$. 